OPEN ACCESS

Edited by:

Yang Shen,

Sichuan University, China

Reviewed by:

Marie-José Goumans,

Leiden University Medical Center,

Netherlands

Juhui Qiu,

Chongqing University, China

*Correspondence:

Jose Luis Martin-Ventura

jlmartin@fjd.es

Carmen Roncal

croncalm@unav.es

tORCID:

Jose Luis Martin-Ventura

0000-0003-2090-8641

Carmen Roncal

0000-0003-0616-9600

Specialty section:

This article was submitted to Molecular and Cellular Pathology,

a section of the journal

Frontiers in Cell and Developmental

Biology

Received: 12 November 2021 Accepted: 10 January 2022

Published: 26 January 2022

Citation:

Martin-Ventura JL, Roncal C, Orbe J and Blanco-Colio LM (2022) Role of

Extracellular Vesicles as Potential

Diagnostic and/or Therapeutic

Biomarkers in Chronic

Cardiovascular Diseases.

Front. Cell Dev. Biol. 10:813885

doi: 10.3389/fcell.2022.813885

\section{Role of Extracellular Vesicles as Potential Diagnostic and/or Therapeutic Biomarkers in Chronic Cardiovascular Diseases}

\author{
Jose Luis Martin-Ventura ${ }^{1,2 * t}$, Carmen Roncal ${ }^{2,3 * t}$, Josune Orbe ${ }^{2,3}$ and \\ Luis Miguel Blanco-Colio ${ }^{1,2}$
}

${ }^{1}$ Vascular Research Laboratory, IIS-Fundación Jiménez-Díaz, Madrid, Spain, ${ }^{2}$ CIBER de Enfermedades Cardiovasculares (CIBERCV), Madrid, Spain, ${ }^{3}$ Laboratory of Atherothrombosis, Program of Cardiovascular Diseases, Cima Universidad de Navarra, Instituto de Investigación Sanitaria de Navarra, IdiSNA, Pamplona, Spain

Cardiovascular diseases (CVDs) are the first cause of death worldwide. In recent years, there has been great interest in the analysis of extracellular vesicles (EVs), including exosomes and microparticles, as potential mediators of biological communication between circulating cells/plasma and cells of the vasculature. Besides their activity as biological effectors, EVs have been also investigated as circulating/systemic biomarkers in different acute and chronic CVDs. In this review, the role of EVs as potential diagnostic and prognostic biomarkers in chronic cardiovascular diseases, including atherosclerosis (mainly, peripheral arterial disease, PAD), aortic stenosis (AS) and aortic aneurysms (AAs), will be described. Mechanistically, we will analyze the implication of EVs in pathological processes associated to cardiovascular remodeling, with special emphasis in their role in vascular and valvular calcification. Specifically, we will focus on the participation of EVs in calcium accumulation in the pathological vascular wall and aortic valves, involving the phenotypic change of vascular smooth muscle cells (SMCs) or valvular interstitial cells $(\mathrm{IC})$ to osteoblast-like cells. The knowledge of the implication of EVs in the pathogenic mechanisms of cardiovascular remodeling is still to be completely deciphered but there are promising results supporting their potential translational application to the diagnosis and therapy of different CVDs.

Keywords: extracelular vesicles, vascular smooth muscle cells, calcification, aneurysm, peripheral arterial disease

\section{CARDIOVASCULAR DISEASES}

CVDs, including heart, coronary, cerebrovascular, peripheral and aortic diseases, are the leading cause of morbidity and mortality in developed countries (Mannello and Medda, 2012). Atherosclerosis, considered the major precursor of CVDs, is a chronic pathology affecting large and medium size arteries that begins early in life, and progresses silently from its subclinical form to clinical symptoms according to the exposure to environmental risk factors (cholesterol, diabetes, hypertension, smoking, stress, sedentarism, microbioma, etc), and non-modifiable determinants such as age (Bray et al., 2021; Libby, 2021). Despite the therapeutic advances in controlling traditional risk factors, and the irruption of novel approaches including targeting inflammation, CVDs remain the primary cause of mortality worldwide, accounting for almost a third of annual deaths, 17.3 


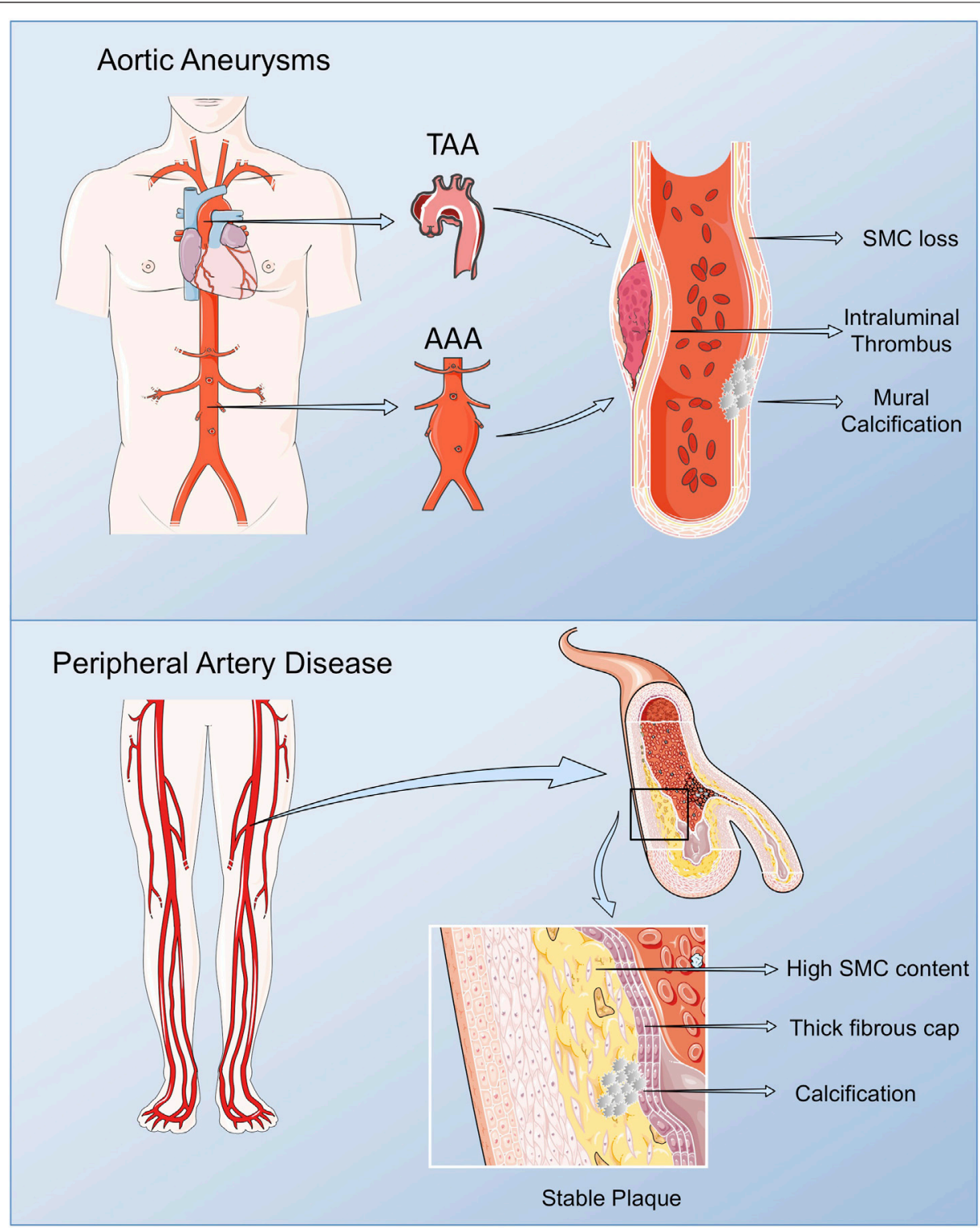

FIGURE 1 | Pathological vascular remodeling. Arterial remodeling in peripheral arteries and thoracic and abdominal aortas present some phenotypic particularities compared with vascular lesions in other vascular beds. Lower limb lesions are most frequently stable with low macrophage content, and a prevalence of vascular SMCs, resulting in plaques rich in collagen and elastic fibers, mostly calcified, with a non-significant lipid core. AAAs are characterized by the presence of an Intra Luminal Thrombus (ILT), rich in red blood cells (RBCs), neutrophils and platelets, and an aortic wall with low number of vascular SMCs in the remaining media, along with immune cell infiltrates, fibroblasts and neovessels in the adventitia. TAA display extensive remodeling of the ECM, vascular SMCs dysfunction and calcification, but ILT is not present. Figure created using Servier Medical Art images (https://smart.servier.com).

million per year, that are expected to grow to more than 23.6 million by 2030 due to lifestyle changes and aging (Roth et al., 2017). Arterial alterations can go unnoticed until symptoms develop, a sign of advanced disease, and thus are associated to a high risk of ischemic complications and death (Acosta et al., 2006; Roth et al., 2017; Timmis et al., 2020). In this context, extracellular vesicles (EVs) emerge as new players in the crosstalk between vascular and circulating cells, participating in cell to cell communication processes, and being biomarkers of cellular activation (Méndez-barbero et al., 2021).

\section{Peripheral Arterial Disease}

PAD includes a range of non-coronary arterial syndromes caused by alterations in the structure and function of arteries other than those supplying the heart or the brain, although in the current review, we will focus on lower extremity $\mathrm{PAD}$ referring to the chronic lower limb ischemia of atherosclerotic origin affecting the femoral, popliteal and saphenous arteries (Gerhard-Herman et al., 2017; Frank et al., 2019). PAD affects around 200 million people worldwide, and increases with age, presenting a prevalence of $10-25 \%$ in people older than 55 years, rising up to 
$40 \%$ on those older than 80 . PAD is associated to a diminished quality of life affecting mobility, and in its more severe form, chronic limb threatening ischemia (CLTI), it might lead to limb amputation, and mortality in high rates (Fowkes et al., 2017). Taking in consideration that PAD is frequently accompanied by atherosclerosis in other vascular beds, it presents a superior risk of ischemic events and death compared with other CV pathologies (Fowkes et al., 2013; Jirak et al., 2018). As such, when associated with other comorbidities, specifically diabetes, the gold standard for PAD diagnosis, the ankle brachial index, losses sensitivity due to arterial calcification, contributing to its silent rates (Hajibandeh et al., 2017; Jirak et al., 2018). In consequence, and despite its bad prognosis, $\mathrm{PAD}$ still remains greatly underdiagnosed and undertreated (Norgren et al., 2007). The morphological analysis of femoral plaques revealed some differences when compared with those in coronary and cerebral arteries. In lower limb lesions, macrophage content is lower, while vascular SMCs are predominant, originating plaques rich in collagen and elastic fibers, mostly calcified, with a nonsignificant lipid core (Derksen et al., 2010; Kamenskiy et al., 2018). This phenotype stabilizes the plaque, slows its progression, and enables the activation of compensatory mechanisms, including collateral circulation, in surrounding tissues (Poredoš et al., 2021) (Figure 1).

\section{Aortic Valve Stenosis}

Degenerative AS is the most frequent form of acquired valvular heart disease in the developed countries, and the second most frequent cause for cardiac surgery, which prevalence will further increase with the aging of the population. The prevalence of AS in patients older than 75 years of age is $12.4 \%$, and $3.4 \%$ have severe AS with an associated risk of death of $50 \%$ at 2 years (Iung and Vahanian, 2006; Nkomo et al., 2006; Kanwar et al., 2018). Normal aortic valves are composed of valvular endothelial cells (ECs), the ICs and extracellular matrix (ECM), while pathological aortic valves are characterized by endothelial dysfunction, lipoprotein accumulation, chronic inflammation, and calcium nodule deposits. Consequently, these pathological changes lead to the thickening and stiffness of the valve leaflets, restricting their opening and imposing an increased afterload on the left ventricle (O'Brien, 2006; Sritharen et al., 2017). Despite the associated clinical consequences, there is currently no effective therapy for AS other than aortic valve replacement (Aymond et al., 2021; Mantovani et al., 2021).

\section{Aortic Aneurysms}

AAs occurs when the progressive weakening of the aortic wall causes the aorta to enlarge and exceeds more than $3 \mathrm{~cm}$. AAs are usually asymptomatic and are often detected as an incidental finding during the investigation of an unrelated problem or as a consequence of radiological screening. The only way to prevent aortic rupture or disection in patients with an AAs $>5-5.5 \mathrm{~cm}$ is surgery (Klink et al., 2011; Milewicz and Ramirez, 2019). AAs can be distinguished by their etiology into degenerative aneurysms and those associated with hereditary disorders or by their different location into abdominal aortic aneurysm (AAA) or thoracic aortic aneurysm (TAA) (Sakalihasan et al., 2005;
Pinard et al., 2019). AAA is a major health problem, causing about $1-2 \%$ of male deaths in economically developed societies. TAA is a relatively common condition, found in up to $8 \%$ of men aged $>65$ years, and is responsible for considerable cardiovascular morbidity and mortality.

AAA share main $\mathrm{CV}$ risk factors with atherosclerosis, while the major risk factors for TAA are hypertension and an underlying genetic alteration or the presence of a bicuspid aortic valve (BAV). AAA is characterized by the presence of an Intra Luminal Thrombus (ILT), mainly composed by red blood cells (RBCs), neutrophils and platelets and an aortic wall with reduced number of vascular SMCs in the remaining media, along with immune cell infiltrates, fibroblasts and neovessels in the adventitia (Michel et al., 2011). Despite the origin of AAA still being poorly understood, proteolysis, oxidative stress, vascular SMCs phenotypic switch and apoptosis, immune-inflammatory responses and neoangiogenesis are mechanisms implicated in the formation and progression of AAA (Torres-Fonseca et al., 2019). Although AAA and TAA share some common mechanisms including proteolytic elastic tissue degeneration and vascular SMCs dysfunction, they present some striking differences: presence (AAA) or abscence (TAA) of ILT; secondary (AAA) versus primary (TAA) pathology of vascular SMCs; linkage (AAA) or not (TAA) to atheroma; monogenic (TAA) versus polygenic (AAA) determinants; age and gender issues (Michel et al., 2018; Martin-Blazquez et al., 2021) (Figure 1).

\section{EXTRACELLULAR VESICLES}

EVs are spherical lipid bilayers without nucleus, released to the extracellular space by most cell types, containing lipids, proteins, metabolites and nucleic acids from the cell of origin. The lipid bilayer protects EVs content from the activity of endogenous DNases, RNases or proteinases, and temperature or $\mathrm{pH}$ changes, and enables their separation from all body fluids and cell culture medium (Momen-Heravi et al., 2018) (Figure 2).

EVs are produced and released to the bloodstream in physiological and pathological conditions by all vascular and circulating cells, displaying a wide range of functions in the vasculature and in target tissues (Giró et al., 2021). The biological activities of EVs in recipient cells are displayed through different mechanisms (Russell et al., 2019). For instance, they can participate in receptor-ligand interactions promoting the activation of signaling pathways in host cells, release their content to the cytoplasm of recipient cells by fusion with the plasma membrane, or be internalized through endocytosis, phagocytosis or micropinocytosis. Finally, by carrying bioactive molecules in their surface, EVs can directly modify target proteins or ECMs components (van Niel et al., 2018). In this way, EVs regulate vascular homeostasis and participate in a myriad of pathological processes, including atherosclerosis initiation and progression, and aortic wall dilation (Méndez-barbero et al., 2021; Saenz-pipaon et al., 2021). Moreover, being their cargo particular to the cell type and the stimuli triggering their release, the analysis of their content might be useful to understand the pathophysiological 


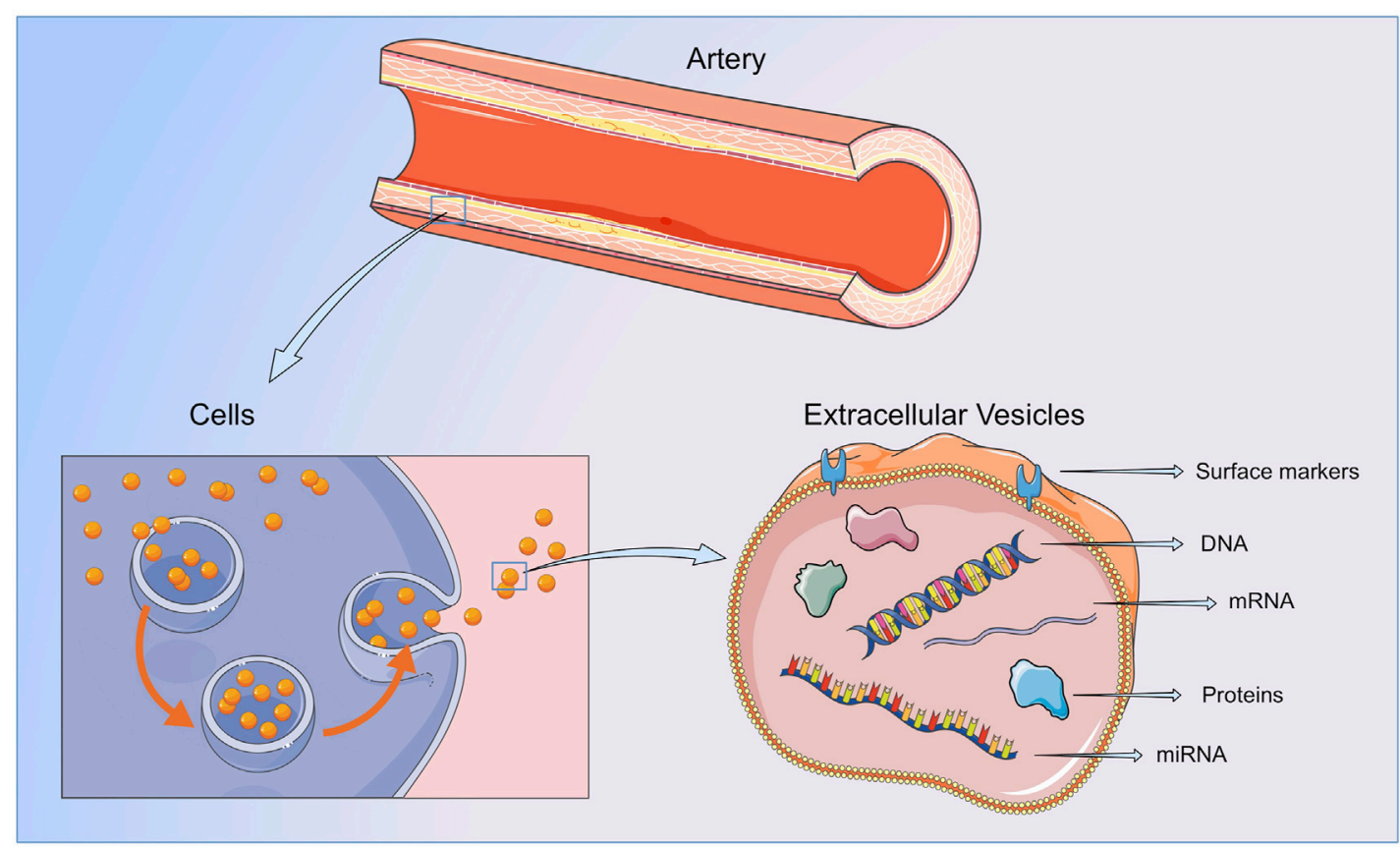

FIGURE 2 | Extracellular vesicles. EVs contain lipids, protein and nucleic acids from the cell or organ of origin and are released to the bloodstream by all cellular components of the vasculature and blood. By transferring their content to neighboring or distant cells or by direct interaction with the ECMs components, EVs are able to participate in all the steps of vessel remodeling. Figure created using Servier Medical Art images (https://smart.servier.com).

condition on which they have been originated (Shah et al., 2018; Théry et al., 2018). In addition, EVs can lead to the identification of novel diagnostic and prognostic biomarkers and therapeutic targets.

Traditionally, EVs have been classified according to their size and biogenesis in: exosomes, with diameters from 30 to $150 \mathrm{~nm}$, generated by the inward budding of the endosomal membrane (Colombo et al., 2014); microvesicles, directly shed from the plasma membrane and polydisperse in size $(100-1000 \mathrm{~nm}$ of diameter) (Connor et al., 2010; Boulanger et al., 2017; Taylor et al., 2020) and apoptotic bodies, generated in the late steps of programmed cell death with diameters of 1000-5,000 nm (Théry et al., 2018; van Niel et al., 2018). However, due to the significant overlap in size and composition between exosomes and microvesicles and following the latter recommendations (Théry et al., 2018), in this review we will use the umbrella term EVs to refer to exosomes and microvesicles (Théry et al., 2018; Russell et al., 2019).

\section{EXTRACELLULAR VESICLES AND CARDIOVASCULAR DISEASES}

EVs have attracted considerable interest in the CV field as reservoirs of molecules produced during arterial remodelling, and/or after acute or chronic ischemic events (Giró et al., 2021), and thus have been proposed as biomarkers in different $\mathrm{CV}$ conditions (Table 1). Likewise, increased levels of total EVs or specific EVs subpopulation, for instance those derived from platelet, ECs, erythrocytes or leukocytes, have been associated with the presence of CV risk factors (Amabile et al., 2014), including diabetes ( $\mathrm{Li}$ et al., 2016), hypertension (Preston et al., 2003), hypercholesterolemia (Amabile et al., 2014) and smoking (Gordon et al., 2011), and with subclinical and clinical atherosclerosis (Suades et al., 2015; Saenz-Pipaon et al., 2020). In coronary pathologies, circulating EVs have been correlated with inflammatory and thrombophilic conditions. As such the number of endothelial and platelet derived EVs have been correlated with the circulating levels of IL- 6 and CRP in patients with coronary heart disease (Cui et al., 2013); moreover in vitro, medium size vesicles from acute coronary syndrome patients displayed procoagulant activity, which was prevented when phosphatidylserine was blocked with lactadherin (Liu et al., 2016). EVs have been also postulated as markers of carotid plaque instability, reporting increased levels of platelet, endothelial, leukocyte and erythrocyte EVs in patients with myocardial infarction when compared with subjects with unstable and stable angina (Cui et al., 2013; Wekesa et al., 2014; Schiro et al., 2015; Liu et al., 2016; Suades et al., 2016; Vagida et al., 2016). Similar results were obtained when assessing the number of tissue factor and annexin $\mathrm{V}$ positive procoagulant EVs subpopulations (Cui et al., 2013; Wekesa et al., 2014). Coronary patients also displayed increased levels of endothelial EVs according to worse vascular function (Amabile et al., 2005; Koga et al., 2005; Werner et al., 2006), and an association between elevated endothelial and erythrocyte EVs and CV events has been also reported (Sinning et al., 2011; Fan et al., 2014; Giannopoulos et al., 2014). Furthermore, in stroke patients elevated levels of 
TABLE 1 | Summary of studies showing a correlation between the levels of total or specific cell type EVs subpopulations, measured by flow cytometry, in circulation (plasma) and cardiovascular diseases.

\begin{tabular}{|c|c|c|c|}
\hline $\begin{array}{l}\text { Disease/patient group } \\
\text { ( } n=\text { number) }\end{array}$ & EVs type & Outcome & References \\
\hline $\begin{array}{l}844 \text { individuals of the Framingham Offspring cohort } \\
\text { (mean age } 66+9 \text { years, } 57 \% \text { women) without } \\
\text { cardiovascular disease }\end{array}$ & 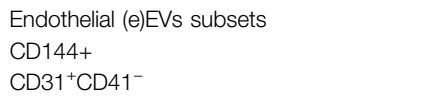 & $\begin{array}{l}\text { Association of eEVs with hypertension, triglycerides } \\
\text { and metabolic syndrome and the Framingham risk } \\
\text { score }\end{array}$ & $\begin{array}{l}\text { Amabile et al. } \\
(2014)\end{array}$ \\
\hline $\begin{array}{l}\text { Systemic review and meta-analysis of } 48 \text { studies } \\
\text { involving } 2,460 \text { patients with type } 2 \mathrm{DM} \text { and } \\
1,880 \text { non-diabetic controls }\end{array}$ & Specific surface markers & $\begin{array}{l}\text { Total EVs, pEVs, mEVs and eEVs were higher in type } \\
2 \text { DM vs. controls }\end{array}$ & (Li et al., 2016) \\
\hline $\begin{array}{l}\text { Three groups: 1) untreated patients with severe } \\
\text { uncontrolled hypertension, } n=24 ; \text { 2) untreated } \\
\text { patients with established mild hypertension, } n=19 \text {; } \\
\text { and 3) normotensive volunteer subjects } n=16\end{array}$ & $\begin{array}{l}\text { eEVs: CD } 31^{+} \mathrm{CD} 42^{-} \\
\text {Platelet }(p) E V s: C D 41^{+}\end{array}$ & $\begin{array}{l}\text { eEVs and pEVs were significantly increased in the } \\
\text { severely hypertensive group }\end{array}$ & $\begin{array}{l}\text { Preston et al. } \\
(2003)\end{array}$ \\
\hline $\begin{array}{l}\text { Two groups: 1) High cardiovascular risk patients ( } n= \\
\text { 37); 2) age, gender, and treatment-matched } \\
\text { controls ( } n=37)\end{array}$ & $\begin{array}{l}\text { Total EVs (Annexin V+) } \\
\text { pEVs } \\
\text { TSP1+ } \\
\text { PAC+ } \\
\text { PAC + CD62P+ } \\
\text { Tissue factor (TF)+ pEVs: CD142 + TSP1+ } \\
\text { TF + monocyte (m)EVs: CD142 + CD14 }\end{array}$ & $\begin{array}{l}\text { Total EVs, pEVs, mEVs, and TF + EVs were } \\
\text { significantly elevated in high risk patients vs. controls } \\
\text { Levels of TF + mEVs and pEVs were associated to } \\
\text { atherosclerotic burden }\end{array}$ & $\begin{array}{l}\text { Suades et al. } \\
(2015)\end{array}$ \\
\hline $\begin{array}{l}\text { Four groups: } 40 \text { patients with myocardial infarction } \\
\text { (MI), } 30 \text { unstable angina (UA), } 20 \text { stable angina (SA), } \\
\text { and } 20 \text { healthy individuals }\end{array}$ & $\begin{array}{l}\text { pEVs: CD41 } 1^{+} \\
\text {mEVs: CD14 } \\
\text { Lymphocytes (l)EVs: CD4 }{ }^{+} \\
\text {eEVs: CD144+ } \\
\text { TF + EVs: CD142+ }\end{array}$ & $\begin{array}{l}\text { eEVs and pEVs were significantly elevated in Ml and } \\
\text { UA vs SA and control } \\
\text { No differences were observed in mEVs and IEVs } \\
\text { among the groups } \\
\text { TF + EVs were higher in Ml and UA } \\
\text { eEVs and pEVs levels correlated with IL-6 or CRP in } \\
\text { coronary heart disease patients }\end{array}$ & Cui et al. (2013) \\
\hline
\end{tabular}

Patients with newly diagnosed acute coronary Total EVs: Lactadherin+ syndrome (ACS) were divided into 3 groups: 1) UA pEVs: CD41a+ $(n=36), 2)$ NSTEMI $(n=22)$, and 3) STEMI $(n=42) ; \quad$ eEVs: CD31 ${ }^{+}$ and an additional group of $n=10$ age and sex matched controls

mEVs: CD14 ${ }^{+}$
B-cells EVs: CD19+

T cells EVs: $\mathrm{CD}^{+}$

Erythrocyte (ery)EVs: CD235a + TF + EVs: CD142+

CAD patients undergoing endarterectomy $(n=42), \quad$ Ann $V+E V s$ and age- and sex-matched controls $(n=73)$

\author{
pEVs subsets \\ $\mathrm{CD} 41^{+}$ \\ Ann $\mathrm{V}+\mathrm{CD} 41^{+}$ \\ eEVs subsets \\ $\mathrm{CD} 31^{+} \mathrm{CD} 41^{-}$ \\ CD144+ \\ CD146+ \\ CD105+
}

Total EVs, pEVs and eEVs were higher in ACS groups Liu et al. (2016) vs controls

Leu- and eryEVs were higher in the STEMI group vs

UA and NSTEMI groups (both $p<0.05$ )

In vitro, EVs form ACS patients displayed procoagulant activity

Annexin V + EVs and pEVs subsets, were higher in cases vs. controls

Wekesa et al. (2014)

eEVs subsets were higher in patients with unstable vs. stable plaques

eEVs and pEVs were significantly higher in patients with carotid stenosis vs. controls

eEVs: Ann V + CD31 ${ }^{+} \mathrm{CD} 42 \mathrm{~b}-$ pEVs: Ann $V+C D 31^{+} \mathrm{CD} 42 \mathrm{~b}+$

Patients undergoing carotid endarterectomy: $n=19$ asymptomatic and $n=51$ symptomatic patients ( $n=$ 51); and $n=20$ healthy age-matched controls

STEMI patients $(n=40)$ treated by percutaneous coronary intervention ( $\mathrm{PCl})$; age, gender, risk factors and pharmacological treatments matched control group ( $n=20)$; and patients recovering from STEMI $(n=20)$
No differences were observed between asymptomatic vs. symptomatic patients

STEMI patients present increased levels of total EVs, Suades et al. LeuEVs subsets, eEVs subsets and PEVs (2016)
Total EVs (Ann V+)

eEVs

$\mathrm{CD} 31^{+}$

CD146+

CD62E+

pEVs: $C D 61^{+}$

Leukocytes (leu)EVs: CD45

IEVs: CD45+/CD3+

mEVs: CD14 ${ }^{+}$ 
TABLE 1 | (Continued) Summary of studies showing a correlation between the levels of total or specific cell type EVs subpopulations, measured by flow cytometry, in circulation (plasma) and cardiovascular diseases.

\begin{tabular}{|c|c|c|c|}
\hline Disease/patient group & EVs type & Outcome & References \\
\hline & $\begin{array}{l}\text { neutrophil EVs: CD66b+ } \\
\text { TF + EVs: CD142+ }\end{array}$ & & \\
\hline 17 healthy volunteers and 13 ACS. & $\begin{array}{l}\text { Magnetic nanoparticles conjugated with anti- } \\
\text { CD63/CD31 or anti-CD31 for eEVs, or with anti- } \\
\text { CD63/CD41a or anti-CD41a antibodies for pEVs }\end{array}$ & $\begin{array}{l}\text { ACs patients presented increased levels of EVs, } \\
\text { mainly of platelet origin }\end{array}$ & $\begin{array}{l}\text { Vagida et al. } \\
\text { (2016) }\end{array}$ \\
\hline $\begin{array}{l}44 \text { end-stage renal failure patients (ESRF), and } 32 \\
\text { healthy subjects }\end{array}$ & $\begin{array}{l}\text { Ann V + EVs } \\
\text { eEVs subsets } \\
\text { CD31 } 1^{+} \\
\text {CD144+ } \\
\text { pEVs: CD41 }{ }^{+} \\
\text {eryEVs: CD235a+ } \\
\text { Lymphocyte EVs: CD3 }{ }^{+} \\
\text {myeloid EVs: CD11b+ } \\
\text { LeuEVs: CD45 } \\
\text { Neutrophil EVs: CD66b+ }\end{array}$ & $\begin{array}{l}\text { Annexin V + EVs, eEVs, pEVs and eryEVs were } \\
\text { increased in ESRF patients vs. controls } \\
\text { Only eEVs correlated with arterial dysfunction }\end{array}$ & $\begin{array}{l}\text { Amabile et al. } \\
\text { (2005) }\end{array}$ \\
\hline 232 patients with DM and 102 controls & $\begin{array}{l}\text { eEVs: CD144 + CD42b- } \\
\text { In DM patients, eEVs were associated to a higher } \\
\text { risk for CAD }\end{array}$ & eEVs levels were increased in DM vs. control & Koga et al. (2005) \\
\hline CAD patients $(n=50)$ & eEVs: CD31 + Ann V+ & $\begin{array}{l}\text { Increased eEVs correlated with worse endothelial- } \\
\text { dependent vasodilatation and independently } \\
\text { predicted severe endothelial dysfunction }\end{array}$ & $\begin{array}{l}\text { Werner et al. } \\
\text { (2006) }\end{array}$ \\
\hline CAD patients $(n=200)$ & eEVs: CD31 + Ann V+ & $\begin{array}{l}\text { eEVs were increased in patients with a first major } \\
\text { adverse cardiovascular and cerebral events (MACCE) } \\
\text { In the follow up eEVs were independently associated } \\
\text { to higher risk of CV death, need for revascularization } \\
\text { or MACCE. }\end{array}$ & $\begin{array}{l}\text { Sinning et al. } \\
(2011)\end{array}$ \\
\hline
\end{tabular}

Healthy controls $(n=80)$, chest paint patients: non- eEVs: CD146+ $\operatorname{CAD}(n=94), \operatorname{SA}(n=111)$, and ACS $(n=145)$

or MACCE.

The levels of eEVs were increased in ACS > SA > Fan et al. (2014) non-CAD > controls

eEVs levels were associated to higher risk of MACE in

ACS group

STEMI patients $(n=51)$ and age-matched controls Ann $V+$ EVs

$(n=50)$

pEVs: $C D 41^{+}$

eryEVs: CD235a+

eryEVs were increased in STEMI patients vs. controls

No differences were found in $\mathrm{pEvs}$

Giannopoulos

eryEVs levels were independently associated to a

higher risk of MACE during the follow-up

Stroke patients: 1) mild stroke, $n=20 ; 2$ )

moderate-severe stroke, $n=21$; 3) age-matched

controls, $n=23$

CD105 + CD144+ $(\mathrm{C}+\mathrm{eEVs})$

Patients with acute stroke ( $n=73)$, and patients with vascular risk factors but no stroke events $(n=275)$
eEVs subsets

CD105 + CD41a-CD45- (E + eEVs)

CD105 + PS + CD41a- (PS + eEVs)

CD105 + CD54+CD45- (I+ eEVs)

eEVs subsets

CD31+/CD42b-

CD31+/AV+

eEVs subsets

CD144 + CD41a-

$\mathrm{CD} 31^{+} \mathrm{CD} 41 \mathrm{a}-$

CD62E+

Ann $\mathrm{V}+\mathrm{CD} 62 \mathrm{E}+$

$\mathrm{PS}+\mathrm{eEV}$ s were increased in stroke patients vs.

controls

All eEVs subsets were elevated in moderate-severe

stroke patients vs. controls

Brain lesion volume was correlated $\mathrm{E}+\mathrm{eEVs}, \mathrm{PS}+$ eEVs and I+ eEVs levels

Levels of CD31+/AnnV+ and CD62E + eEVs subsets Jung et al. (2009) were greater in acute stroke patients vs. controls CD62E + eEVs were strongly associated with stroke severity and infarct volume

CD62E

CD144+/CD41a-, CD31+CD41a-, CD62E+, and Li and Qin (2015) Annexin V + CD62E + eEVs, were significantly increased in acute ischemic stroke patients vs. controls

CD144+/CD41a- eEVs were correlated with stroke severity

Simak et al. (2006)

pEVs: CD41a + CD144- 
TABLE 1 | (Continued) Summary of studies showing a correlation between the levels of total or specific cell type EVs subpopulations, measured by flow cytometry, in circulation (plasma) and cardiovascular diseases.

\begin{tabular}{|c|c|c|c|}
\hline $\begin{array}{l}\text { Disease/patient group } \\
\text { ( } n=\text { number) }\end{array}$ & EVs type & Outcome & References \\
\hline 18 PAD patients and 12 asymptomatic controls & $\begin{array}{l}\text { Total EVs: Lactadherin+ } \\
\text { pEVs: CD41a+ } \\
\text { eEVs subsets } \\
\text { CD31 }{ }^{+} \\
\text {CD144 + } \\
\text { LeuEVs: CD45 }{ }^{+}\end{array}$ & $\begin{array}{l}\text { PAD patients presented increased levels of eEVs } \\
\text { carrying the monomeric form of C-reactive protein } \\
\text { (mCRP) } \\
\text { Control subjects on statins presented a reduction in } \\
\text { mCRP + eEVs }\end{array}$ & $\begin{array}{l}\text { Crawford et al. } \\
(2016)\end{array}$ \\
\hline & $\begin{array}{l}\text { mEVs: CD14 } \\
\text { B-cells EVs: CD19 }\end{array}$ & & \\
\hline
\end{tabular}

T cells EVs: CD3 ${ }^{+}$
Neutrophil EVs: CD66b+

eryEVs: CD235a+

Monomeric $(m)$ or pentameric $(p)$ CRP + EVs

\begin{tabular}{|c|c|c|c|}
\hline PAD patients $(n=50)$ and controls $(n=50)$ & $\begin{array}{l}\text { eEVs: CD144+ } \\
\text { pEVs: CD42b+ } \\
\text { LeuEVs: CD } 45^{+}\end{array}$ & $\begin{array}{l}\text { PAD patients present increased levels of shh+ in all } \\
\text { EVs subpopulations } \\
\text { Shh }+ \text { eEVs levels correlated with the number of } \\
\text { collateral vessels in ischemic thighs of PAD patients } \\
(n=18)\end{array}$ & $\begin{array}{l}\text { Giarretta et al. } \\
\text { (2018) }\end{array}$ \\
\hline & $\begin{array}{l}\text { eryEVs: CD235+ } \\
\text { Sonic Hedgedog (Shh)+EVs }\end{array}$ & & \\
\hline PAD patients $(n=50)$ and controls $(n=50)$ & pEVs: CD41 ${ }^{+}$ & Increased levels of pEVs in PAD patients vs controls & Zeiger et al. (2000) \\
\hline $\begin{array}{l}\text { PAD patients, } n=23 \text { with severe disease (critical } \\
\text { limb ischemia, CLI), } 36 \text { with moderate disease }\end{array}$ & pEVs: CD61+CD42b+ & $\begin{array}{l}\text { Gradual increased in pEVs levels according ro } \\
\text { severity (CLI > IC > controls) }\end{array}$ & Tan et al. (2005) \\
\hline
\end{tabular}

(intermittent claudication, $\mathrm{IC}$ ), and $n=30$ healthy

controls

\begin{tabular}{|c|c|c|c|}
\hline $\begin{array}{l}\text { Patients presenting stable angina }(n=10) \text {, peripheral } \\
\text { arterial disease }(n=10) \text {, NSTEMI }(n=11) \text { and STEMI } \\
\text { myocardial infarction }(n=10) \text {, age- and sex matched } \\
\text { older controls } n=10 \text { and young healthy individuals } \\
(n=10)\end{array}$ & $\begin{array}{l}\text { pEVs subsets } \\
\text { Ann } V+C D 61^{+} C D 62 P+ \\
\text { Ann } V+C D 61^{+} C D 63^{+} \\
\text {eEVs: CD62E } \\
\text { EryEVs: CD235a } \\
\text { T- cells EVs } \\
\text { CD4 + } \\
\text { CD8 }{ }^{+} \\
\text {mEVs: CD14 } \\
\text { B cells EVs: CD20 } \\
\text { Neutrophil EVs: CD66e+ }\end{array}$ & $\begin{array}{l}\text { 96\% of the detected EVs were from platelet origin } \\
\text { CD62P + pEVs increased in patients with NSTEMI } \\
\text { and STEMl vs. older controls } \\
\text { CD63+pEVs- were increased in patients with PAD, } \\
\text { NSTEMI, and STEMl vs. older controls }\end{array}$ & $\begin{array}{l}\text { van der Zee et al. } \\
\text { (2006) }\end{array}$ \\
\hline PAD patients $(n=45)$ & $\begin{array}{l}\text { AnnexinV } \\
\text { eEVs: CD62E+ } \\
\text { pEVs: CD41/61+ } \\
\text { LeuEVs: CD11b+ } \\
\text { eryEVs: CD235a+ } \\
\text { More than } 85 \% \text { of pEVs and eryEVs were Ann } V_{+} \text {, } \\
\text { while the percentage was lower for eEVs (70\%) } \\
\text { and LeuEVs (40\%) } \\
\text { The number pEVs were inversely correlated with } \\
\text { procoagulant activity of plasma }\end{array}$ & $\begin{array}{l}\text { In plasma of PAD patients pEVs were the most } \\
\text { abundant subpopulation, followed by eryEVs, eEVs } \\
\text { and LeuEVs }\end{array}$ & $\begin{array}{l}\text { Saenz-Pipaon } \\
\text { et al. (2020) }\end{array}$ \\
\hline $\begin{array}{l}14 \text { PAD patients and } 15 \text { normal controls } \\
\text { PAD patients were treated with cilostazol ( } 2 \text { weeks) } \\
\text { or cilostazol with dipyridamole ( } 14 \text { weeks) }\end{array}$ & pEVs: $\mathrm{CD} 42^{+}$ & $\begin{array}{l}\text { PAD patients presented increased levels of pEVs } \\
\text { Cilostazol, and further, cilostazol with dipyridamole } \\
\text { decreased pEVs levels in PAD patients }\end{array}$ & $\begin{array}{l}\text { Nomura et al. } \\
\text { (2004) }\end{array}$ \\
\hline $\begin{array}{l}\text { PAD patients }(n=19) \text { randomly assigned to } \\
\text { Atorvastatin or placebo treatment for } 8 \text { weeks }\end{array}$ & $\begin{array}{l}\text { Total EVs: lactadherin } \\
\text { pEVs } \\
\text { CD42a + CD142+ } \\
\text { CD42a + CD62P+ } \\
\text { CD42a + CD61 }\end{array}$ & $\begin{array}{l}\text { Atorvastatin treatment reduced the number of } \\
\text { CD142+, CD62P+ and } C D 61^{+} \text {pEVs vs placebo } \\
\text { treated PAD patients }\end{array}$ & $\begin{array}{l}\text { Mobarrez et al. } \\
\text { (2011) }\end{array}$ \\
\hline $\begin{array}{l}\text { PAD patients }(n=19) \text { randomly assigned to } \\
\text { Atorvastatin or placebo treatment for } 8 \text { weeks }\end{array}$ & $\begin{array}{l}\text { Total EVs } \\
\text { eEVs }\end{array}$ & (Continued on $f$ & $\begin{array}{l}\text { Mobarrez et al. } \\
\text { (2012) } \\
\text { llowing page) }\end{array}$ \\
\hline
\end{tabular}


TABLE 1 | (Continued) Summary of studies showing a correlation between the levels of total or specific cell type EVs subpopulations, measured by flow cytometry, in circulation (plasma) and cardiovascular diseases.

Disease/patient group $\quad$ EVs type References
( $n=$ number)

\begin{tabular}{|c|c|c|c|}
\hline & $\begin{array}{l}\text { Lactdherin + CD144+ } \\
\text { Lactadherin + CD144 + CD142+ }\end{array}$ & $\begin{array}{l}\text { Both CD144 + eEVs and CD144 + CD142+ eEVs } \\
\text { were increased in patients on atorvastatin vs. } \\
\text { placebo }\end{array}$ & \\
\hline $\begin{array}{l}22 \text { patients with severe aortic stenosis (AS) and } 18 \\
\text { controls }\end{array}$ & $\begin{array}{l}\text { eEVs: CD62E+ } \\
\text { pEVs } \\
\text { CD31 } 1^{+} \text {CD61 } 1^{+} \\
\text {CD62P+ } \\
\text { LeuEVs: CD11b+ }\end{array}$ & $\begin{array}{l}\text { pEVs, LeuEVs and eEVs were increased in AVS } \\
\text { patients vs. control } \\
\text { pEVs levels were correlated with shear stress and } \\
\text { eEVs with the number of blood monocytes }\end{array}$ & Diehl et al. (2008) \\
\hline $\begin{array}{l}\text { Patients with severe AS. } n=28 \text { with low coronary } \\
\text { calcification (CAC) score, and } n=27 \text { with high CAC } \\
\text { score }\end{array}$ & $\begin{array}{l}\text { eEVs } \\
\text { CD144+ } \\
\text { CD62E+ } \\
\text { CD31 }{ }^{+} \mathrm{CD} 41^{-} \\
\text {pEVs: CD41 } 1^{+} \\
\text {EVs trombin generation activity }\end{array}$ & $\begin{array}{l}\text { The levels of pEVs and CD62E + eEVs were } \\
\text { increased in high CAC score patients vs. low CAC } \\
\text { score group, and correlated to the calcium score } \\
\text { EVs thrombin generation activity was higher in } \\
\text { patients with high CAC score }\end{array}$ & Horn et al. (2016) \\
\hline
\end{tabular}

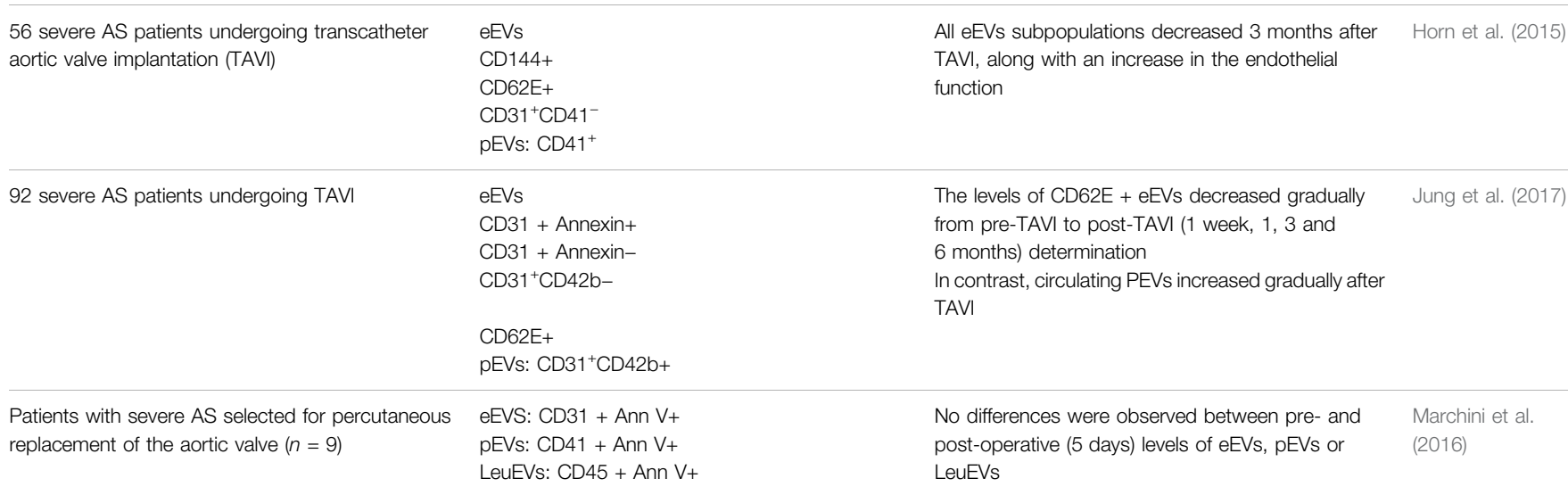

$\begin{array}{ll}\begin{array}{l}135 \text { patients undergoing surgical aortic valve } \\ \text { replacement }\end{array} & \begin{array}{l}\text { small (s)EVs were quantified by nanoparticle } \\ \text { tracking analysis (NTA) }\end{array}\end{array}$ replacement tracking analysis (NTA)
sEVs decreased $24 \mathrm{~h}$ post-surgery, and recovered to Weber et al. (2020) pre-operative levels 7 days and 3 months postprocedure

No association between sEVs and echocardiographic parameters before or after surgery (7 days and 3 months) were observed sEVs levels were correlated to prosthesis patients mismatch parameters at month 3 post-surgery

AAA patients (blood samples and mural thrombi, $n=$ Annexin $V+E V s$ 20), and sex and age-matched healthy individuals pEVs: CD41 (blood samples, $n=20$ )

Circulating total EVs were significantly increased in Touat et al. (2006) AAA patients vs. controls neutrophil EVs CD15 mEVs: CD14
Locally, luminal thrombus layers released larger quantities of annexin V-positive EV, mainly of platelet and neutrophil origin, compared to the intermediate and abluminal layers

eEVs: CD106

eryEVs: CD235

Controls $(n=66)$ and thoracic AA (TAA) patients Ann V + EVs associated to bicuspid aortic valves (BAV) $(n=15), \quad$ pEVs: Ann V + CD41 $1^{+}$ or other origins (degenerative, $n=23$ )
The levels of EVs and pEVs were higher in TAA groups vs. control

AAA: abdominal aortic aneurysm; ACS: acute coronary syndrome; AS: aortic stenosis; TAA: Thoracic aortic aneurysm; TAVI: transcatheter aortic valve implantation; CAD: coronary artery disease; CAC: coronary calcification score; DM: diabetes mellitus; ESRF: end-stage renal failure; CLI: critical limb ischemia; IC: Intermittent claudication; MI: myocardial infarction; PAD: peripheral arterial disease; SA: stable angina; UA: unstable angina; Ann V: Annexin V; EVs: Extracellular vesicles; eEVs: endothelial EVs; eryEVs: erythrocyte EVs; LeuEVs: leukocyte EVs; IEVs: Lymphocyte EVs; mEVs: monocyte EVs; pEVs: platelet EVs; (N)STMI: (non) ST Segment Elevation Myocardial Infarction; TF: Tissue factor; TSP-1: Thrombospondin-1; T; PAC: activated $\alpha$ llb $\beta 3$-integrin. 
specific subpopulations of endothelial derived EVs were associated to worse outcome (Simak et al., 2006; Jung et al., 2009; Li and Qin, 2015). In PAD, circulating EVs are mainly considered platelet activation markers (Zeiger et al., 2000; SaenzPipaon et al., 2020), while in AAA, EVs were enriched in proteins involved in the main pathological mechanisms leading to AAA development and progression, including oxidative stress, inflammation and thrombosis (Martinez-Pinna et al., 2014). Besides their role as biomarkers, EVs display biological activities and induce cellular responses in vitro and in vivo also during vessel remodelling, modulating endothelial (dys) function, leukocyte recruitment, foam cell formation, VSMCs proliferation and migration, apoptosis and necrotic core formation, plaque rupture and thrombosis. This topic has been extensively addressed in recent reviews (Zarà et al., 2019; Giró et al., 2021; Patel et al., 2021).

\section{Extracellular Vesicles: Potential Biomarkers and Biological Effectors in Peripheral Arterial Disease}

EVs have been investigated as biomarkers and biological effectors in PAD, displaying different effects according to their cargo and origin. It has been proposed that the elevated levels of endothelial EVs co-expressing the monomeric form of C-reactive protein (CRP) might potentially contribute to inflammation in PAD (Crawford et al., 2016), while endothelial cell derived EVs rich in the pro-angiogenic Sonic hedgehog protein correlated with the number of collateral vessels in ischemic thighs of PAD patients, suggesting their possible role in neovascularization (Giarretta et al., 2018). Among the different EVs lineages, platelet EVs, seemed to be most abundant in plasma of PAD patients (SaenzPipaon et al., 2020), and their elevated numbers were correlated with PAD diagnosis and prognosis (Zeiger et al., 2000; Tan et al., 2005; van der Zee et al., 2006). It should be considered, however, that within total platelet EVs, only those co-exposing either P-selectin or CD63 might reflect the degree of platelet activation in vitro (van der Zee et al., 2006). Based on those data, it has been suggested the potential benefit of modifying total EVs numbers or subpopulations by pharmacological treatments (Rosińska et al., 2017). As such, cilostazol induced a reduction in the total number of platelet EVs in PAD patients (Nomura et al., 2004), while atorvastatin modified specific platelet EVs subpopulations, reducing those positive for P-selectin, tissue factor and glycoprotein-IIIa (Mobarrez et al., 2011). Interestingly, atorvastatin displayed the opposite effect on endothelial EVs inducing their increase in circulation (Mobarrez et al., 2012).

EVs also encapsulate nucleic acids, mainly mRNA and noncoding RNAs, from the cells or organs of origin, that can be released to the circulation and display biological responses in neighboring or distant cells. As such, small EVs from PAD patients enriched in miR-21, miR-92a, miR-126, miR-143, miR-181b, and miR-221, increased vascular SMCs migration in vitro and inhibited that of ECs when compared with EVs from control patients (Sorrentino et al., 2020). Further, these authors also described that small EVs induced M1 polarization marker expression in macrophages in vitro, regardless of the pathophysiological condition from which EVs were isolated, control or PAD (Sorrentino et al., 2020). Moreover, the study of the transcriptional content of EVs might lead to the identification of new diagnosis and prognosis biomarkers, and therapeutic targets in PAD. In this regard, we found an upregulation of the S100A9 transcript after RNA-Seq analysis of plasma EVs in PAD patients (Saenz-Pipaon et al., 2020). Interestingly, as previously described (Engelberger et al., 2015; Dann et al., 2018), the protein encoded by S100A9, in circulation forming the heterocomplex S100A8/A9 or calprotectin, was elevated in PAD patients compared with controls and associated with a higher risk of mortality or amputation in the follow-up (Saenz-Pipaon et al., 2020), suggesting the potential of studying EVs content to identify novel biomarkers in chronic vascular diseases.

Regarding the biological activity of EVs, several authors have investigated their function in experimental models of hind limb ischemia using as source blood, tissues or cell culture conditioned medium. As such, in a rat model of femoral ischemia, platelet EVs from atherosclerotic patients increased the adhesion capacity of circulating angiogenic cells to the ischemic muscles and increased neovascularization, which was prevented when the coculture of EVs and circulating angiogenic cells was pretreated with a RANTES neutralizing antibody (Ohtsuka et al., 2013). In mouse, the proangiogenic effect of bone marrow-mononuclear cells was increased when administered together with EVs isolated from ischemic muscles in a mechanisms dependent on gp91 (Leroyer et al., 2009), while T lymphocyte-derived EVs enriched in Sonic hedgehog protein improved muscle recovery in a mechanism dependent on nitric oxide production (Benameur et al., 2010). Moreover, EVs from ETS variant transcription factor 2 transfected fibroblasts, increased neovascularization (Van Pham et al., 2017). In addition, recent findings indicate that the beneficial effects of stem cells in skeletal muscle repair might be partially mediated by EVs. As such, several authors reported improved muscle recovery by the intramuscular delivery of EVs generated by stem cells of different types, including mesenchymal, adipocyte, $\mathrm{CD} 34^{+}$or urine-derived (Hu et al., 2015; Gangadaran et al., 2017; Mathiyalagan et al., 2017; Ju et al., 2018; Lopatina et al., 2018; Zhu et al., 2018; Figliolini et al., 2020; Zhang et al., 2021). Overall, EVs seem to participate in all steps of vascular and muscle remodelling in PAD.

\section{Extracellular Vesicles: Possible Diagnostic and Prognostic Biomarkers in Aortic Stenosis}

The possible utilization of EVs as diagnostic and prognostic biomarkers in AS, although still scarley studied, has been also addressed by several authors. Diehl et al. reported increased levels of leukocyte, platelet and endothelial derived EVs in patients with severe AS compared to controls (Diehl et al., 2008). In addition, they found a positive correlation between platelet and endothelial EVs, and shear stress and blood leukocyte numbers, respectively, in AS patients (Diehl et al., 2008). Other authors described that subjects with severe AS and high coronary calcification score 
presented elevated levels of circulating endothelial and platelet derived EVs, and augmented EVs-associated thrombin activity, when compared with AS subjects with low coronary calcification score (Horn et al., 2016), suggesting the involvement of EVs in endothelial dysfunction, inflammation and valvular calcification.

Regarding the possible role of EVs as biomarkers for outcome assessment after valvular replacement, Marchini et al. found no differences in the concentration of total EVs, or in the levels of endothelial, platelet or leukocyte EVs early after surgery (5 days) compared to pre-procedure levels (Marchini et al., 2016). However, other authors reported a gradual decrease in endothelial EVs at longer time periods post-valvular replacement (1, 3 and 6 months) (Horn et al., 2015; Jung et al., 2017), accompanied by an improvement in the endothelial function (Horn et al., 2015) and an increase in platelet EVs (Jung et al., 2017). When it comes to small EVs or exosomes, their numbers acutely decrease after surgical valve replacement ( $24 \mathrm{~h}$ ), going back to pre-operative levels 7 days and 3 months post-procedure, suggesting no alteration of small EVs release in response to valvular replacement (Weber et al., 2020). However, in a subgroup of patients, these authors described a positive correlation between increased levels of small EVs and patient-prosthesis mismatch parameters, and suggested the possible prognostic value of small EVs to estimate emerging patient-prosthesis mismatch and adverse outcomes in patients undergoing surgical aortic valve replacement (Weber et al., 2020). Locally, the ex vivo release of Annexin $\mathrm{V}+\mathrm{EV}$ s to the conditioned medium was similar in ortic valves from patients suffering calcified AS of different origins, and no correlation between the released EVs and calcium content was observed (Kochtebane et al., 2013). Even if the summarized data points towards a role of EVs as biological effectors and biomarkers in AS, larger studies are needed to clarify their involment in the processes leading to AS initiation and progression.

\section{Biological Role of Extracellular Vesicles in Aortic Aneurysms}

As mentioned above, blood-borne EVs are mainly derived from activated platelets (Burnier et al., 2009), although leukocytes, red blood cells and ECs can also participate (Nomura, 2017). In this respect, platelet-derived EVs are increased in plasma of AAA patients (Touat et al., 2006) and TAA (Touat et al., 2008). Following a proteomic approach, we described increased ficolin-3 levels in EVs isolated from the plasma of patients with AAA (Martinez-Pinna et al., 2014). We also showed that ficolin-3 levels were increased in EVs of platelets from healthy subjects incubated with ADP, as well as in EVs isolated from AAA thrombus-conditioned media (Fernandez-García et al., 2017). The number of particles was higher in activated platelets and pathological tissue compared with healthy aorta. In addition, by flow cytometry, we observed that staining for platelets, and also leukocytes, was increased in EVs obtained from thrombus, compared with those from healthy aorta. Finally, ficolin-3 levels in plasma were associated to both AAA presence and evolution, suggesting its potential role as a diagnostic and prognostic biomarker (Fernandez-García et al., 2017). In addition, the contribution of neutrophils (Folkesson et al., 2015) and macrophages (Wang et al., 2019) to the release of EVs in human AAA was previously demonstrated. Moreover, in a latter study, the authors demonstrated that inhibiting small EVs biogenesis decreased experimental AAA associated to a reduction in MMP-2 expression (Wang et al., 2019), describing a pathogenic role of macrophage-derived small EVs production in AAA. Regarding TAA, where inflammatory cells are not present, vascular SMCs were tested to contribute to EVs release. In this study (Jia et al., 2017), mechanical stretch induced EVs production by vascular SMCs, which depended on endoplasmic reticulum (ER) stress. This process led to EC dysfunction and contributed to TAA formation, while an ER stress inhibitor blocked EV production in vitro and TAA formation and rupture. In addition, Han et al. demonstrated an upregulation of miR-106a in small EVs from plasma and tissue-conditioned media of AAA patients (Han et al., 2020). Interestingly, the authors demonstrated a pathogenic role of miR106 , by favoring vascular SMCs apoptosis and ECM degradation. However, the cell type involved in miR-106 upregulation was not identified. Moreover, treatment with EVs from mesenchymal stromal cells decreased AAA development and macrophage activation in mice by inducing miR-147 (Spinosa et al., 2018). All these data suggest a potential contribution of EVs with a positive or negative effect on AAs mechanisms and progression that depends on the cells of origin and the stimuli triggering EVs release.

\section{ROLE OF EXTRACELLULAR VESICLES IN PATHOLOGICAL MECHANISMS INVOLVED IN VASCULAR REMODELING}

\section{Extracellular Vesicles and Phenotype Switch of Resident Vascular and Valvular Cells}

Cardiovascular remodeling is a main driver of CVD, where vascular SMCs and valvular ICs play a central role. Most vascular SMCs in the vessel wall display a contractile phenotype, which allows them to maintain vascular tone. However, under pathological vascular remodeling, it is well established that vascular SMCs loses their contractile phenotype to one resembling other cell types. Novel technologies including vascular SMCs lineage tracing, single cell (sc)RNAseq of mouse and human atherosclerotic vessels, and human genomics, demonstrate a multipotential fate of dedifferentiated vascular SMCs to cell types including foam cells, osteochondrocytes or myofibroblasts, among others (Wirka et al., 2019; Pan et al., 2020; Hu Z. et al., 2021). Moreover, numerous studies have demonstrated the ability of valvular ICs to undergo osteogenic trans-differentiation (Rajamannan et al., 2005; Osman et al., 2006; Chen et al., 2009; Monzack and Masters, 2011). Similarly, vascular SMCs phenotypic switch, as shown by loss of contractility markers and increases in matrix metalloproteinases, preceded aortic aneurysm in mice. Very recently, it has been demonstrated that aneurysm 
formation was driven by extensive reprogramming of contractile medial vascular SMCs to mesenchymal stem cell (MSC)- derived cell types including adipocytes, chondrocytes, osteoblasts, as well as macrophages that increased over time (Chen et al., 2020). The progressive accumulation of these cells provoked the loss of elastin fibers, intramural calcifications, massive lipid uptake and extensive inflammation. All this data supports the importance of vascular SMCs and valvular ICs phenotypic switch in pathological cardiovascular remodeling, although the exact impact of each phenotype is still under debate.

Regarding the potential contribution of EVs to vascular SMCs phenotypic switch, the incubation of human vascular SMCs with platelet EVs decreased the expression of contractile proteins, while inducing a synthetic proinflammatory phenotype resulting in increased IL-6 secretion and vascular SMCs migration and proliferation, through mechanisms involving CD40 and P-selectin interactions (Vajen et al., 2017). Under uremic conditions, EC-derived EVs stimulated vascular SMCs proliferation via TGF-beta (Ryu et al., 2019). Treatment with endothelial EVs reduced the proliferation and migration of vascular SMCs as well as lipid accumulation in vascular SMCs, while this beneficial effect was abolished or even reversed when treated with LPS-derived endothelial cell EVs (Xiang et al., 2021). ECs stimulated with oxysterol 7-ketocholesterol induced NLRP3 inflammasome activation and increased secretion of EVs that contain IL-1 $\beta$. These EC-EVs rich in IL-1 $\beta$ promoted synthetic phenotype transition of co-cultured vascular SMCs, whereas EVs from unstimulated ECs had the opposite effects (Yuan et al., 2020). These last two recent results suggest a potential protective effect of EC-derived EVs on vascular SMCs, which seem to be impaired when produced under proinflammatory conditions, mimicking the pathological vascular wall.

\section{The Role of Extracellular Vesicles in Vascular Calcification}

Calcification has been associated to several CVDs, including atherosclerosis, aortic valve stenosis and aortic aneurysm. Calcium arterial coronary (CAC) score is a marker of $\mathrm{CV}$ events (Detrano et al., 2008). Initially, aortic valve calcification was also associated with cardiovascular events, although the association was attenuated after CAC was taken into account (Owens et al., 2012). More recently, it has been demonstrated that aortic valve calcification is independently associated with allcause and $\mathrm{CV}$ deaths in patients with low coronary atherosclerosis burden (Han et al., 2021). Similarly, calcification in either the thoracic or the abdominal territory, has also been suggested as a potential contributor to aneurysm progression and mortality (Buijs et al., 2013; Chowdhury et al., 2018). The association of calcification with CV events depends on the arterial territory affected (Allison et al., 2012), but this association also differs between microcalcifications $(<50 \mu \mathrm{m})$ or macrocalcifications (O'Neill et al., 2015). Macrocalcification in carotid atherosclerotic lesions correlated with a transcriptional profile typical for stable plaques, with altered vascular SMCs phenotype and ECM composition, and repressed inflammation (Karlöf et al., 2019). In contrast, microcalcifications that are present in high-risk atheroma, predicts adverse cardiovascular events, and is associated with increased morbidity and mortality (McEvoy et al., 2010). More recently, a prospective observational study has demonstrated that $18 \mathrm{~F}-\mathrm{FDG}$ and $18 \mathrm{~F}-\mathrm{NaF}$ PET/CT performed in the superficial femoral artery before and 6 weeks after angioplasty identified patients who would develop restenosis within 12 months (Chowdhury et al., 2020). Finally, in the prospective SoFIA3 study, aneurysms with higher 18F-fluoride uptake had 2.5 times more rapid aneurysm expansion, and experienced three times more AAA repair or rupture, compared with patients with less aneurysmal microcalcification (Forsythe et al., 2018). The deleterious effect of microcalcification on AAA expansion was further demonstrated in the experimental model of AngII (angiotensin II)-induced AAA in mice (Li et al., 2020). In this study, vascular SMCs-specific ablation of Runx2 (runt-related transcription factor 2) abrogated microcalcification and inhibited AngIIinduced AAA formation. Similarly, conditional depletion of Runx2 in valvular ICs and sinus wall cells of LDLr-/ -ApoB100 mice (a model of calcified aortic valve disease) improved aortic valve function by decreasing aortic valve calcification (Dharmarajan et al., 2021). All these data highlights the importance of vascular SMCs and valvular ICsinduced calcification in cardiovascular remodeling.

Previous studies identified vascular SMCs or valvular ICs expressing markers of osteochondrocytes, along with decreased expression of endogenous inhibitors of calcification, in pathological arteries and aortic valve lesions (Boström et al., 1993; O’Brien et al., 1995; Mohler et al., 2001; Rajamannan et al., 2003; Tyson et al., 2003; Dubis et al., 2016). There are several potential inducers of vascular SMCs or valvular ICs to an osteocondrogenic phenotype in atherosclerotic plaques, valves and aneurysms, including apoptosis, oxidative stress, mitochondrial dysfunction and probably, inflammation (through paracrine factors secreted by inflammatory cells) (Dweck et al., 2012; Durham et al., 2018; P ; Petsophonsakul et al., 2019). These modified vascular SMCs and valvular ICs favor vascular calcification through the release of calcifying EVs, a subpopulation traditionally known as matrix vesicles (MVs) (Shanahan et al., 2011). Later studies demonstrated that MVs are exosomes and show that factors that can increase exosome release can promote vascular calcification in response to environmental calcium stress (Kapustin et al., 2015). Interestingly, this study demonstrated that the inhibition of exosome release by a sphingomyelin phosphodiesterase 3 inhibitor blocks calcification. In addition, macrophages could also release calcifying EVs in atherosclerotic plaques and aortic valves (New et al., 2013; Passos et al., 2020).

Calcification, initially thought to be a passive process of calcium/phosphate precipitation in the ECMs, is nowadays described as an active-cell mediated process, which begins by aggregation of calcifying extracellular vesicles and the formation of microcalcifications, ultimate leading to large areas of calcification (Hutcheson et al., 2016). There are several events involved in vascular calcification, with a key role of EVs cargo as mediators of this process (Figure 3). The EVs cargo can be modified under a prolonged mineral imbalance and/or an 


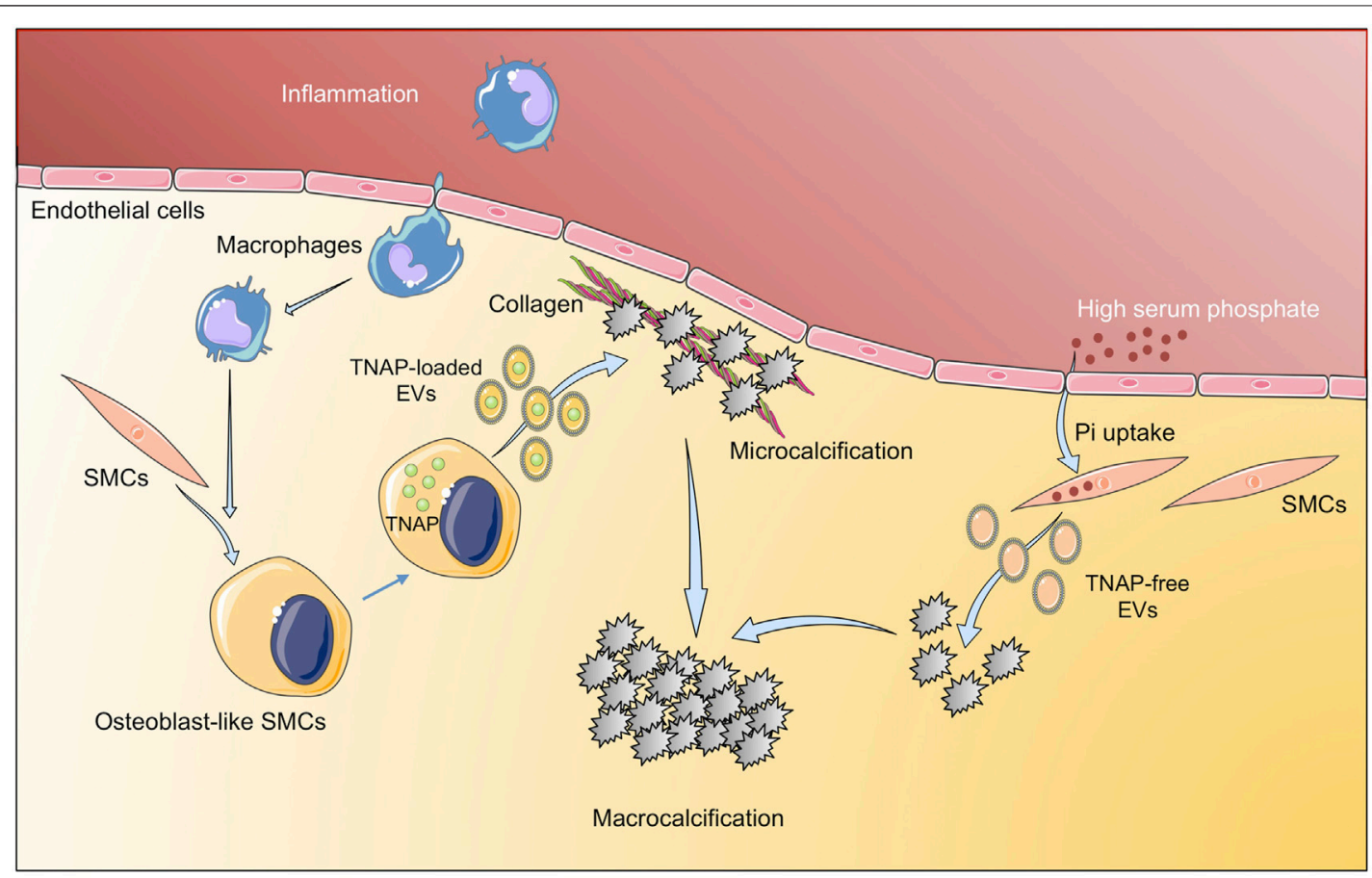

FIGURE 3 | Implication of extracellular vesicles in vascular calcification. Inflammatory environment induces osteogenic differentiation of SMC to osteoblast-like SMCs that release TNAP-loaded EV that aggregate into microcalcifications. In addition, high serum phosphate induces tissue calcification through EV with low TNAP. Figure created using Servier Medical Art images (https://smart.servier.com).

inflammatory environment, which results in a reduction of calcification inhibitors inside EVs and their enrichment in protein-lipid complexes consisting of phosphatidylserine (PS) and Annexin A6 (Kapustin et al., 2011). Tissue nonspecific alkaline phosphatase (TNAP), a key enzyme during calcification through the hydrolysis of extracellular pyrophosphate into phosphate, has been also found in vascular SMCs- derived calcifying EVs (Chen et al., 2008). Interestingly, phosphate-induced calcification increased the expression and activity of TNAP in cultured vascular SMCs with a osteocondrogenic phenotype (Villa-Bellosta, 2018), and the overexpression of TNAP is sufficient to induce medial calcification in aortic rings ex vivo (Villa-Bellosta et al., 2011). During the calcification process, TNAP along with annexins, mediates the interaction of EVs released by vascular SMCs and valvular ICs with the ECMs (predominantly type I collagen), initiating the mineralization process (Côté et al., 2012; Mathieu et al., 2014). Thus, some studies have tried to interfere with the mediators/molecular pathways involved in the production and release of calcifying EVs, and/or with those participating in the switch of vascular SMCs to the chondrogenic phenotype. In this respect, one of the most studied mediators is discoidin domain receptor-1 (DDR-1), a collagen-binding tyrosine kinase receptor that regulates vascular calcification and atherosclerosis (Ahmad et al., 2009). Interestingly, DDR-1 (-/-) vascular SMCs exhibited a 4-fold increase in EV release with elevated TNAP activity (Krohn et al., 2016). Very recently, it has been demonstrated that DDR-1 regulates the transdifferentiation of vascular SMCs to osteochondrocytic cells by sensing matrix stiffening during disease progression and transmitting contractile forces through the actin cytoskeleton (Ngai et al., 2020). Another study highlighting the importance of EVs cargo described a novel mechanism involving sortilin, a member of the vacuolar protein sorting 10 protein family of sorting receptors, that has been related to calcification and CVDs (Goettsch et al., 2018). Interestingly, sortilin induced calcification by favoring the loading of activated TNAP into EVs, which was independent of vascular SMCs osteochondrogenic reprogramming and did not affect bone mineralization (Goettsch et al., 2016). Moreover, lossand gain-of-function studies, did not reveal a sortilin-dependent change in the number and size of EVs from calcifying vascular SMCs, further supporting that sortilin-induced calcification is dependent on the modulation of EVs cargo rather than on EVs number or subpopulation. More recently, Annexin A1, a protein associated with calcium binding and intracellular endosomal transport, has been identified as a main component in EVs present in atherosclerotic plaques and has been involved in EV tethering, leading to aggregation and ectopic calcification (Rogers et al., 2020a). Similar to EVs derived from calcifying vascular SMCs, the pro-calcified valvular ICs derived EVs showed up-regulation of several annexins. An in vitro study demonstrated EVs secretion with elevated calcium and Annexin A6 from rat VICs cultured with high calcium and phosphate and suggested a role in calcified aortic valve disease evidenced by co-localization of Annexin A6 with EVs in the aortic valve (Cui et al., 2017). In addition to TNAP and annexins as mediators of cardiovascular 
calcification associated to their presence in EVs, other pathways have been studied. Two recent studies have analyzed the contribution of the Nox-5 subunit of NADPH oxidase in vascular calcification involving both, vascular SMCs phenotypic switch and EVs production. In a former study, it was demonstrated that switching from contractile to synthetic phenotype was required for vascular SMCs calcification, and that $\mathrm{Ca}^{2+}$-dependent Nox5 expression increased oxidative stress, leading to elevated vascular SMCs-EVs release and subsequent calcification (Furmanik et al., 2020). More recently, the same group described that Nox 5 was also the underlying mechanism by which nicotine induced vascular SMCs calcification and EV secretion, further supporting the role of smoking in pathological vascular remodeling and calcification (Petsophonsakul et al., 2021).

In spite of all this progress on the knowledge of mechanisms involved in cardiovascular calcification, there are currently no approved drugs to prevent or treat calcification (Aikawa and Blaser, 2021). Regarding potential therapeutic strategies based on natural compounds, oligogalacturonic acid (present in smooth pectin regions of the apple cell wall matrix) reduced vascular calcification by inhibition of osteogenic phenotype of vascular SMCs, and also by preventing EVs binding to type I collagen (Hodroge et al., 2017). A recent study tested the role of retinoids on vascular calcification, showing that acyclic retinoid inhibited cardiovascular cell calcification by attenuating TNAP activity and Runx2 expression without adverse effects on bone mineralization (Rogers et al., 2020b). However, these studies need to be performed in vivo to test its potential application. In this respect, a selective and orally bioavailable TNAP inhibitor attenuated the development of calcification in mice in vivo, without the deleterious effects on bone associated with other proposed treatment strategies (Ziegler et al., 2017; Tani et al., 2020); however, whether these strategies involved EVs and whether they could be applied in models of pathological cardiovascular remodeling deserve further studies.

\section{CONCLUSION}

Circulating EVs have been postulated as potential biomarkers in CVDs, as their absolute numbers, or the number of specific subpopulations have been associated to the incidence and prognosis of CVDs. In order to find novel biomarkers, different approaches on EVs have been used, from analysis of vascular SMCs-derived EVs under mineralization conditions (Kapustin et al., 2011), to AAA-tissue-derived EVs (Fernandez-García et al., 2017; Han et al., 2020) or plasma EVs from atherosclerotic patients (Madrigal-Matute et al., 2014; SaenzPipaon et al., 2020), among others. However, while many of these biomarkers demonstrate prognostic associations with CVD clinical outcomes, future research will be required to clarify their mechanistic roles and their potential clinical utility. Furthermore, current advances in -Omic approaches, mainly focused on improving sensitivity, will be crucial to dissect the molecular content of EVs in different pathological conditions, leading to the identification of differentially expressed RNAs, protein or metabolites, that will help to delineate the molecular profiles of different CVDs, and to identify novel diagnosis and prognosis biomarkers, as well as therapeutic targets.

In addition, EVs-based therapeutics have been proposed for several pathologies, including CVDs (Herrmann et al., 2021). Recently, the coating of stents with EVs resulted in accelerated reendothelization and reduced instent re-stenosis compared to drugeluting or bare-metal stents in mice (Hu S. et al., 2021). Similarly, the administration of EVs secreted by immortalized cardiospherederived cells, engineered to express high levels of b-catenin, modulated the immune response and improved cardiac function in an experimental model of cardiomyophaty in mice (Lin et al., 2021). We can thus envision the possibility to engineer EVs to modify their cargo and prevent vascular calcification and pathological remodeling. In this respect, Ldlr mRNA was encapsulated into EVs and then injected in atherosclerotic LDLR null mice, decreasing both hepatic steatosis and atherosclerotic lesions ( $\mathrm{Li}$ et al., 2021). The translation of these experimental studies to humans is awaiting, and several clinical trials are in progress (Sahoo et al., 2021). At present we are only aware of one study performed with peripheral blood mononuclear cells obtained from patients with anthracycline-induced cardiomyopathy, reprogrammed into induced pluripotent stem cells and differentiated into cardiomyocytes. These cardiomyocytes were treated with EVs from mesenchymal stromal cells resulting in preserved mitochondrial function, augmentation of ATP production, mitigation of ROS production, and suppression of apoptosis (O’Brien et al., 2021), being all these processes involved in vascular calcification and pathological remodeling. In this study, large but not small EVs, had a therapeutic activity, while other studies in different pathologies have suggested the opposite view (Tieu et al., 2021), thus highlighting the need for a better standardization and characterization of the effect of different EVs subpopulations for translational therapeutic purposes.

\section{AUTHOR CONTRIBUTIONS}

JLM-V and CR wrote and edited the manuscript. LMB-C created the figures. LMB-C and JO critically reviewed and edited the manuscript. All authors read, and approved the submitted version.

\section{FUNDING}

This study was funded by the Spanish Ministry of Economy and Competitiveness (PID2019-106814RB-I00), Comunidad Autónoma de Madrid (Complemento II-CM, S2017/BMD3673), Instituto de Salud Carlos III (ISCiii-FEDER) (IPT17/ 0019, PI18/01195, PI19/00065 PI19/00128, and RD21/0006/ 0008) co-funded by European Regional Development Fund "A way to make Europe (ISCiii-FEDER), Spanish Biomedical Research Centre in Cardiovascular Disease (CB16/11/00371 and CB16/11/00333), The Foundation for Applied Medical Research, Universidad de Navarra (Spain) and La Caixa" Banking Foundation (HR17-00247). 


\section{REFERENCES}

Acosta, S., Ögren, M., Bengtsson, H., Bergqvist, D., Lindblad, B., and Zdanowski, Z. (2006). Increasing Incidence of Ruptured Abdominal Aortic Aneurysm: A Population-Based Study. J. Vasc. Surg. 44, 237-243. doi:10.1016/j.jvs.2006. 04.037

Ahmad, P. J., Trcka, D., Xue, S., Franco, C., Speer, M. Y., Giachelli, C. M., et al. (2009). Discoidin Domain Receptor-1 Deficiency Attenuates Atherosclerotic Calcification and Smooth Muscle Cell-Mediated Mineralization. Am. J. Pathol. 175, 2686-2696. doi:10.2353/ajpath.2009.080734

Aikawa, E., and Blaser, M. C. (2021). 2020 Jeffrey M. Hoeg Award Lecture. Atvb 41, 117-127. doi:10.1161/ATVBAHA.120.314704

Allison, M. A., Hsi, S., Wassel, C. L., Morgan, C., Ix, J. H., Wright, C. M., et al. (2012). Calcified Atherosclerosis in Different Vascular Beds and the Risk of Mortality. Arterioscler Thromb. Vasc. Biol. 32, 140-146. doi:10.1161/ ATVBAHA.111.235234

Amabile, N., Cheng, S., Renard, J. M., Larson, M. G., Ghorbani, A., McCabe, E., et al. (2014). Association of Circulating Endothelial Microparticles with Cardiometabolic Risk Factors in the Framingham Heart Study. Eur. Heart J. 35, 2972-2979. doi:10.1093/eurheartj/ehu153

Amabile, N., Guérin, A. P., Leroyer, A., Mallat, Z., Nguyen, C., Boddaert, J., et al. (2005). Circulating Endothelial Microparticles Are Associated with Vascular Dysfunction in Patients with End-Stage Renal Failure. Jasn 16, 3381-3388. doi:10.1681/ASN.2005050535

Aymond, J. D., Benn, F., Williams, C. M., Bernard, M. L., Hiltbold, A. E., Khatib, S., et al. (2021). Epidemiology, Evaluation, and Management of Conduction Disturbances after Transcatheter Aortic Valve Replacement. Prog. Cardiovasc. Dis. 66, 37-45. doi:10.1016/j.pcad.2021.06.004

Benameur, T., Soleti, R., Porro, C., Andriantsitohaina, R., and Martínez, M. C. (2010). Microparticles Carrying Sonic Hedgehog Favor Neovascularization through the Activation of Nitric Oxide Pathway in Mice. PLoS One 5, e12688-10. doi:10.1371/journal.pone.0012688

Boström, K., Watson, K. E., Horn, S., Wortham, C., Herman, I. M., and Demer, L. L. (1993). Bone Morphogenetic Protein Expression in Human Atherosclerotic Lesions. J. Clin. Invest. 91, 1800-1809. doi:10.1172/JCI116391

Boulanger, C. M., Loyer, X., Rautou, P.-E., and Amabile, N. (2017). Extracellular Vesicles in Coronary Artery Disease. Nat. Rev. Cardiol. 14, 259-272. doi:10. 1038/nrcardio. 2017.7

Bray, F., Laversanne, M., Cao, B., Varghese, C., Mikkelsen, B., Weiderpass, E., et al. (2021). Comparing Cancer and Cardiovascular Disease Trends in 20 Middle- or High-Income Countries 2000-19: A Pointer to National Trajectories towards Achieving Sustainable Development Goal Target 3.4. Cancer Treat. Rev. 100, 102290. doi:10.1016/j.ctrv.2021.102290

Buijs, R. V. C., Willems, T. P., Tio, R. A., Boersma, H. H., Tielliu, I. F. J., Slart, R. H. J. A., et al. (2013). Calcification as a Risk Factor for Rupture of Abdominal Aortic Aneurysm. Eur. J. Vasc. Endovascular Surg. 46, 542-548. doi:10.1016/j. ejvs.2013.09.006

Burnier, L., Fontana, P., Kwak, B. R., and Angelillo-Scherrer, A. (2009). Cellderived Microparticles in Haemostasis and Vascular Medicine. Thromb. Haemost. 101, 439-451. doi:10.1160/th08-08-0521

Chen, J.-H., Yip, C. Y. Y., Sone, E. D., and Simmons, C. A. (2009). Identification and Characterization of Aortic Valve Mesenchymal Progenitor Cells with Robust Osteogenic Calcification Potential. Am. J. Pathol. 174, 1109-1119. doi:10.2353/ajpath.2009.080750

Chen, N. X., O’Neill, K. D., Chen, X., and Moe, S. M. (2008). Annexin-mediated Matrix Vesicle Calcification in Vascular Smooth Muscle Cells. J. Bone Mineral Res. 23, 1798-1805. doi:10.1359/jbmr.080604

Chen, P.-Y., Qin, L., Li, G., Malagon-Lopez, J., Wang, Z., Bergaya, S., et al. (2020). Smooth Muscle Cell Reprogramming in Aortic Aneurysms. Cell Stem Cell 26, 542-557. doi:10.1016/j.stem.2020.02.013

Chowdhury, M. M., Tarkin, J. M., Albaghdadi, M. S., Evans, N. R., Le, E. P. V., Berrett, T. B., et al. (2020). Vascular Positron Emission Tomography and Restenosis in Symptomatic Peripheral Arterial Disease. JACC: Cardiovasc. ImagingImaging 13, 1008-1017. doi:10.1016/j.jcmg.2019.03.031

Chowdhury, M. M., Zieliński, L. P., Sun, J. J., Lambracos, S., Boyle, J. R., Harrison, S. C., et al. (2018). Editor's Choice - Calcification of Thoracic and Abdominal
Aneurysms Is Associated with Mortality and Morbidity. Eur. J. Vasc. Endovascular Surg. 55, 101-108. doi:10.1016/j.ejvs.2017.11.007

Colombo, M., Raposo, G., and Théry, C. (2014). Biogenesis, Secretion, and Intercellular Interactions of Exosomes and Other Extracellular Vesicles. Annu. Rev. Cel Dev. Biol. 30, 255-289. doi:10.1146/annurev-cellbio-101512122326

Côté, N., El Husseini, D., Pépin, A., Guauque-Olarte, S., Ducharme, V., BouchardCannon, P., et al. (2012). ATP Acts as a Survival Signal and Prevents the Mineralization of Aortic Valve. J. Mol. Cell Cardiol. 52, 1191-1202. doi:10.1016/ j.yjmcc.2012.02.003

Crawford, J. R., Trial, J., Nambi, V., Hoogeveen, R. C., Taffet, G. E., and Entman, M. L. (2016). Plasma Levels of Endothelial Microparticles Bearing Monomeric C-Reactive Protein Are Increased in Peripheral Artery Disease. J. Cardiovasc. Trans. Res. 9, 184-193. doi:10.1007/s12265-016-9678-0

Cui, L., Rashdan, N. A., Zhu, D., Milne, E. M., Ajuh, P., Milne, G., et al. (2017). End Stage Renal Disease-Induced Hypercalcemia May Promote Aortic Valve Calcification via Annexin VI Enrichment of Valve Interstitial Cell DerivedMatrix Vesicles. J. Cel. Physiol. 232, 2985-2995. doi:10.1002/jcp.25935

Cui, Y., Zheng, L., Jiang, M., Jia, R., Zhang, X., Quan, Q., et al. (2013). Circulating Microparticles in Patients with Coronary Heart Disease and its Correlation with Interleukin-6 and C-Reactive Protein. Mol. Biol. Rep. 40, 6437-6442. doi:10. 1007/s11033-013-2758-1

Dann, R., Hadi, T., Montenont, E., Boytard, L., Alebrahim, D., Feinstein, J., et al. (2018). Platelet-Derived MRP-14 Induces Monocyte Activation in Patients with Symptomatic Peripheral Artery Disease. J. Am. Coll. Cardiol. 71, 53-65. doi:10. 1016/j.jacc.2017.10.072

Derksen, W. J. M., De Vries, J.-P. P. M., Vink, A., Velema, E., Vos, J.-A., De Kleijn, D., et al. (2010). Histologic Atherosclerotic Plaque Characteristics Are Associated with Restenosis Rates after Endarterectomy of the Common and Superficial Femoral Arteries. J. Vasc. Surg. 52, 592-599. doi:10.1016/J.JVS.2010. 03.063

Detrano, R., Guerci, A. D., Carr, J. J., Bild, D. E., Burke, G., Folsom, A. R., et al. (2008). Coronary Calcium as a Predictor of Coronary Events in Four Racial or Ethnic Groups. N. Engl. J. Med. 358, 1336-1345. doi:10.1056/nejmoa072100

Dharmarajan, S., Speer, M. Y., Pierce, K., Lally, J., Leaf, E. M., Lin, M.-E., et al. (2021). Role of Runx2 in Calcific Aortic Valve Disease in Mouse Models. Front. Cardiovasc. Med. 8. doi:10.3389/fcvm.2021.687210

Dubis, J., Litwin, M., Michalowska, D., Zuk, N., Szczepanska-Buda, A., Grendziak, R., et al. (2016). Elevated Expression of Runt-Related Transcription Factors in Human Abdominal Aortic Aneurysm. J. Biol. Regul. Homeost Agents 30, 497-504.

Durham, A. L., Speer, M. Y., Scatena, M., Giachelli, C. M., and Shanahan, C. M. (2018). Role of Smooth Muscle Cells in Vascular Calcification: Implications in Atherosclerosis and Arterial Stiffness. Cardiovasc. Res. 114, 590-600. doi:10. 1093/cvr/cvy010

Dweck, M. R., Boon, N. A., and Newby, D. E. (2012). Calcific Aortic Stenosis. J. Am. Coll. Cardiol. 60, 1854-1863. doi:10.1016/j.jacc.2012.02.093

Engelberger, R. P., Limacher, A., Kucher, N., Baumann, F., Silbernagel, G., Benghozi, R., et al. (2015). Biological Variation of Established and Novel Biomarkers for Atherosclerosis: Results from a Prospective, Parallel-Group Cohort Study. Clinica Chim. Acta 447, 16-22. doi:10.1016/j.cca.2015.05.003

Exner, T., Ma, D. D. F., Joseph, J. E., and Connor, D. E. (2010). The Majority of Circulating Platelet-Derived Microparticles Fail to Bind Annexin V, Lack Phospholipid-dependent Procoagulant Activity and Demonstrate Greater Expression of Glycoprotein Ib. Thromb. Haemost. 103, 1044-1052. doi:10. 1160/TH09-09-0644

Fan, Y., Wang, L., Li, Y., Yin, Z., Xu, Z., and Wang, C. (2014). Quantification of Endothelial Microparticles on Modified Cytometric Bead Assay and Prognosis in Chest Pain Patients. Circ. J. 78, 206-214. doi:10.1253/circj.cj-13-0488

Fernandez-García, C.-E., Burillo, E., Lindholt, J. S., Martinez-Lopez, D., Pilely, K., Mazzeo, C., et al. (2017). Association of Ficolin-3 with Abdominal Aortic Aneurysm Presence and Progression. J. Thromb. Haemost. 15, 575-585. doi:10. $1111 /$ jth. 13608

Figliolini, F., Ranghino, A., Grange, C., Cedrino, M., Tapparo, M., Cavallari, C., et al. (2020). Extracellular Vesicles from Adipose Stem Cells Prevent Muscle Damage and Inflammation in a Mouse Model of Hind Limb Ischemia. Atvb 40, 239-254. doi:10.1161/atvbaha.119.313506 
Folkesson, M., Li, C., Frebelius, S., Swedenborg, J., Wågsäter, D., Williams, K. J., et al. (2015). Proteolytically Active ADAM10 and ADAM17 Carried on Membrane Microvesicles in Human Abdominal Aortic Aneurysms. Thromb. Haemost. 114, 1165-1174. doi:10.1160/TH14-10-0899

Forsythe, R. O., Dweck, M. R., McBride, O. M. B., Vesey, A. T., Semple, S. I., Shah, A. S. V., et al. (2018). 18F-Sodium Fluoride Uptake in Abdominal Aortic Aneurysms. J. Am. Coll. Cardiol. 71, 513-523. doi:10.1016/j.jacc.2017.11.053

Fowkes, F. G. R., Aboyans, V., Fowkes, F. J. I., McDermott, M. M., Sampson, U. K. A., and Criqui, M. H. (2017). Peripheral Artery Disease: Epidemiology and Global Perspectives. Nat. Rev. Cardiol. 14, 156-170. doi:10.1038/nrcardio. 2016.179

Fowkes, F. G. R., Rudan, D., Rudan, I., Aboyans, V., Denenberg, J. O., McDermott, M. M., et al. (2013). Comparison of Global Estimates of Prevalence and Risk Factors for Peripheral Artery Disease in 2000 and 2010: a Systematic Review and Analysis. The Lancet 382, 1329-1340. doi:10.1016/S0140-6736(13)61249-0

Frank, U., Nikol, S., and Belch, J. (2019). 5 Conservative Treatment for PAD - Risk Factor Management. Vasa 48, 1-12. doi:10.1024/0301-1526/a000835

Furmanik, M., Chatrou, M., Van Gorp, R., Akbulut, A., Willems, B., Schmidt, H., et al. (2020). Reactive Oxygen-Forming Nox5 Links Vascular Smooth Muscle Cell Phenotypic Switching and Extracellular Vesicle-Mediated Vascular Calcification. Circ. Res. 127, 911-927. doi:10.1161/CIRCRESAHA.119.316159

Gangadaran, P., Rajendran, R. L., Lee, H. W., Kalimuthu, S., Hong, C. M., Jeong, S. Y., et al. (2017). Extracellular Vesicles from Mesenchymal Stem Cells Activates VEGF Receptors and Accelerates Recovery of Hindlimb Ischemia. J. Controlled Release 264, 112-126. doi:10.1016/j.jconrel.2017.08.022

Gerhard-Herman, M. D., Gornik, H. L., Barrett, C., Barshes, N. R., Corriere, M. A., Drachman, D. E., et al. (2017). 2016 AHA/ACC Guideline on the Management of Patients with Lower Extremity Peripheral Artery Disease: A Report of the American College of Cardiology/American Heart Association Task Force on Clinical Practice Guidelines. Circulation 135, e726-e779. doi:10.1161/CIR. 0000000000000471

Giannopoulos, G., Oudatzis, G., Paterakis, G., Synetos, A., Tampaki, E., Bouras, G., et al. (2014). Red Blood Cell and Platelet Microparticles in Myocardial Infarction Patients Treated with Primary Angioplasty. Int. J. Cardiol. 176, 145-150. doi:10.1016/j.ijcard.2014.07.022

Giarretta, I., Gatto, I., Marcantoni, M., Lupi, G., Tonello, D., Gaetani, E., et al. (2018). Microparticles Carrying Sonic Hedgehog Are Increased in Humans with Peripheral Artery Disease. Ijms 19, 3954. doi:10.3390/ijms19123954

Giró, O., Jiménez, A., Pané, A., Badimon, L., Ortega, E., and Chiva-Blanch, G. (2021). Extracellular Vesicles in Atherothrombosis and Cardiovascular Disease: Friends and Foes. Atherosclerosis 330, 61-75. doi:10.1016/j.atherosclerosis. 2021.07.002

Goettsch, C., Hutcheson, J. D., Aikawa, M., Iwata, H., Pham, T., Nykjaer, A., et al. (2016). Sortilin Mediates Vascular Calcification via its Recruitment into Extracellular Vesicles. J. Clin. Invest. 126, 1323-1336. doi:10.1172/JCI80851

Goettsch, C., Kjolby, M., and Aikawa, E. (2018). Sortilin and its Multiple Roles in Cardiovascular and Metabolic Diseases. Atvb 38, 19-25. doi:10.1161/ ATVBAHA.117.310292

Gordon, C., Gudi, K., Krause, A., Sackrowitz, R., Harvey, B.-G., Strulovici-Barel, Y., et al. (2011). Circulating Endothelial Microparticles as a Measure of Early Lung Destruction in Cigarette Smokers. Am. J. Respir. Crit. Care Med. 184, 224-232. doi:10.1164/rccm.201012-2061OC

Hajibandeh, S., Hajibandeh, S., Shah, S., Child, E., Antoniou, G. A., and Torella, F. (2017). Prognostic Significance of Ankle Brachial Pressure index: A Systematic Review and Meta-Analysis. Vascular 25, 208-224. doi:10.1177/ 1708538116658392

Han, D., Cordoso, R., Whelton, S., Rozanski, A., Budoff, M. J., Miedema, M. D., et al. (2021). Prognostic Significance of Aortic Valve Calcium in Relation to Coronary Artery Calcification for Long-Term, Cause-specific Mortality: Results from the CAC Consortium. Eur. Heart J. Cardiovasc. Imaging 22, 1257-1263. doi:10.1093/ehjci/jeaa336

Han, Z. L., Wang, H. Q., Zhang, T. S., He, Y. X., and Zhou, H. (2020). Upregulation of Exosomal miR-106a May Play a Significant Role in Abdominal Aortic Aneurysm by Inducing Vascular Smooth Muscle Cell Apoptosis and Targeting TIMP-2, an Inhibitor of Metallopeptidases that Suppresses Extracellular Matrix Degradation. Eur. Rev. Med. Pharmacol. Sci. 24, 8087-8095. doi:10.26355/eurrev_202008_22493
Herrmann, I. K., Wood, M. J. A., and Fuhrmann, G. (2021). Extracellular Vesicles as a Next-Generation Drug Delivery Platform. Nat. Nanotechnol. 16, 748-759. doi:10.1038/s41565-021-00931-2

Hodroge, A., Trécherel, E., Cornu, M., Darwiche, W., Mansour, A., Ait-Mohand, K., et al. (2017). Oligogalacturonic Acid Inhibits Vascular Calcification by Two Mechanisms. Atvb 37, 1391-1401. doi:10.1161/ATVBAHA.117.309513

Horn, P., Erkilet, G., Veulemans, V., Kröpil, P., Schurgers, L., Zeus, T., et al. (2016). Microparticle-induced Coagulation Relates to Coronary Artery Atherosclerosis in Severe Aortic Valve Stenosis. PLoS One 11, e0151499. doi:10.1371/journal. pone.0151499

Horn, P., Stern, D., Veulemans, V., Heiss, C., Zeus, T., Merx, M. W., et al. (2015) Improved Endothelial Function and Decreased Levels of Endothelium-Derived Microparticles after Transcatheter Aortic Valve Implantation. EuroIntervention 10, 1456-1463. doi:10.4244/EIJY14M10_02

Hu, G.-w., Li, Q., Niu, X., Hu, B., Liu, J., Zhou, S.-m., et al. (2015). Exosomes Secreted by Human-Induced Pluripotent Stem Cell-Derived Mesenchymal Stem Cells Attenuate Limb Ischemia by Promoting Angiogenesis in Mice. Stem Cel Res. Ther. 6. doi:10.1186/SCRT546

Hu, S., Li, Z., Shen, D., Zhu, D., Huang, K., Su, T., et al. (2021a). Exosome-eluting Stents for Vascular Healing after Ischaemic Injury. Nat. Biomed. Eng. 5, 1174-1188. doi:10.1038/s41551-021-00705-0

Hu, Z., Liu, W., Hua, X., Chen, X., Chang, Y., Hu, Y., et al. (2021b). Single-Cell Transcriptomic Atlas of Different Human Cardiac Arteries Identifies Cell Types Associated with Vascular Physiology. Atvb 41, 1408-1427. doi:10.1161/ ATVBAHA.120.315373

Hutcheson, J. D., Goettsch, C., Bertazzo, S., Maldonado, N., Ruiz, J. L., Goh, W., et al. (2016). Genesis and Growth of Extracellular-Vesicle-Derived Microcalcification in Atherosclerotic Plaques. Nat. Mater 15, 335-343. doi:10.1038/nmat4519

Iung, B., and Vahanian, A. (2006). Valvular Heart Diseases in Elderly People. The Lancet 368, 969-971. doi:10.1016/S0140-6736(06)69216-7

Jia, L.-X., Zhang, W.-M., Li, T.-T., Liu, Y., Piao, C.-M., Ma, Y.-C., et al. (2017). ER Stress Dependent Microparticles Derived from Smooth Muscle Cells Promote Endothelial Dysfunction during Thoracic Aortic Aneurysm and Dissection. Clin. Sci. 131, 1287-1299. doi:10.1042/CS20170252

Jirak, P., Mirna, M., Wernly, B., Paar, V., Thieme, M., Betge, S., et al. (2018). Analysis of Novel Cardiovascular Biomarkers in Patients with Peripheral Artery Disease. Minerva Med. 109, 443-450. doi:10.23736/S0026-4806.18.05628-8

Ju, C., Shen, Y., Ma, G., Liu, Y., Cai, J., Kim, I.-m., et al. (2018). Transplantation of Cardiac Mesenchymal Stem Cell-Derived Exosomes Promotes Repair in Ischemic Myocardium. J. Cardiovasc. Trans. Res. 11, 420-428. doi:10.1007/ s12265-018-9822-0

Jung, C., Lichtenauer, M., Figulla, H.-R., Wernly, B., Goebel, B., Foerster, M., et al. (2017). Microparticles in Patients Undergoing Transcatheter Aortic Valve Implantation (TAVI). Heart Vessels 32, 458-466. doi:10.1007/s00380-0160885-z

Jung, K.-H., Chu, K., Lee, S.-T., Park, H.-K., Bahn, J.-J., Kim, D.-H., et al. (2009). Circulating Endothelial Microparticles as a Marker of Cerebrovascular Disease. Ann. Neurol. 66, 191-199. doi:10.1002/ana.21681

Kamenskiy, A., Poulson, W., Sim, S., Reilly, A., Luo, J., and Mactaggart, J. (2018). Prevalence of Calcification in Human Femoropopliteal Arteries and its Association with Demographics, Risk Factors, and Arterial Stiffness. Atvb 38, e48-e57. doi:10.1161/ATVBAHA.117.310490

Kanwar, A., Thaden, J. J., and Nkomo, V. T. (2018). Management of Patients with Aortic Valve Stenosis. Mayo Clinic Proc. 93, 488-508. doi:10.1016/j.mayocp. 2018.01.020

Kapustin, A. N., Chatrou, M. L. L., Drozdov, I., Zheng, Y., Davidson, S. M., Soong, D., et al. (2015). Vascular Smooth Muscle Cell Calcification Is Mediated by Regulated Exosome Secretion. Circ. Res. 116, 1312-1323. doi:10.1161/ CIRCRESAHA.116.305012

Kapustin, A. N., Davies, J. D., Reynolds, J. L., McNair, R., Jones, G. T., Sidibe, A., et al. (2011). Calcium Regulates Key Components of Vascular Smooth Muscle Cell-Derived Matrix Vesicles to Enhance Mineralization. Circ. Res. 109. doi:10. 1161/CIRCRESAHA.110.238808

Karlöf, E., Seime, T., Dias, N., Lengquist, M., Witasp, A., Almqvist, H., et al. (2019). Correlation of Computed Tomography with Carotid Plaque Transcriptomes Associates Calcification with Lesion-Stabilization. Atherosclerosis 288, 175-185. doi:10.1016/j.atherosclerosis.2019.05.005 
Klink, A., Hyafil, F., Rudd, J., Faries, P., Fuster, V., Mallat, Z., et al. (2011). Diagnostic and Therapeutic Strategies for Small Abdominal Aortic Aneurysms. Nat. Rev. Cardiol. 8, 338-347. doi:10.1038/nrcardio.2011.1

Kochtebane, N., Passefort, S., Choqueux, C., Ainoun, F., Achour, L., Michel, J. B., et al. (2013). Release of Leukotriene B4, Transforming Growth Factor-Beta1 and Microparticles in Relation to Aortic Valve Calcification. J. Heart Valve Dis. 22, 782-788. Available at: https://pubmed.ncbi.nlm.nih.gov/24597398/ (Accessed January 3, 2022).

Koga, H., Sugiyama, S., Kugiyama, K., Watanabe, K., Fukushima, H., Tanaka, T., et al. (2005). Elevated Levels of VE-Cadherin-Positive Endothelial Microparticles in Patients with Type 2 Diabetes Mellitus and Coronary Artery Disease. J. Am. Coll. Cardiol. 45, 1622-1630. doi:10.1016/j.jacc.2005. 02.047

Krohn, J. B., Hutcheson, J. D., Martínez-Martínez, E., Irvin, W. S., Bouten, C. V. C., Bertazzo, S., et al. (2016). Discoidin Domain Receptor-1 Regulates Calcific Extracellular Vesicle Release in Vascular Smooth Muscle Cell Fibrocalcific Response via Transforming Growth Factor- $\beta$ Signaling. Atvb 36, 525-533. doi:10.1161/ATVBAHA.115.307009

Leroyer, A. S., Ebrahimian, T. G., Cochain, C., Re'calde, A., Blanc-Brude, O., Mees, B., et al. (2009). Microparticles from Ischemic Muscle Promotes Postnatal Vasculogenesis. Circulation 119, 2808-2817. doi:10.1161/ CIRCULATIONAHA.108.816710

Li, P., and Qin, C. (2015). Elevated Circulating VE-Cadherin+CD144+Endothelial Microparticles in Ischemic Cerebrovascular Disease. Thromb. Res. 135, 375-381. doi:10.1016/j.thromres.2014.12.006

Li, S., Wei, J., Zhang, C., Li, X., Meng, W., Mo, X., et al. (2016). Cell-Derived Microparticles in Patients with Type 2 Diabetes Mellitus: A Systematic Review and Meta-Analysis. Cell. Physiol. Biochem. 39, 2439-2450. doi:10.1159/ 000452512

Li, Z., Zhao, P., Zhang, Y., Wang, J., Wang, C., Liu, Y., et al. (2021). Exosome-based Ldlr Gene Therapy for Familial Hypercholesterolemia in a Mouse Model. Theranostics 11, 2953-2965. doi:10.7150/THNO.49874

Li, Z., Zhao, Z., Cai, Z., Sun, Y., Li, L., Yao, F., et al. (2020). Runx2 (Runt-Related Transcription Factor 2)-Mediated Microcalcification Is a Novel Pathological Characteristic and Potential Mediator of Abdominal Aortic Aneurysm. Atvb 40, 1352-1369. doi:10.1161/ATVBAHA.119.314113

Libby, P. (2021). The Changing Landscape of Atherosclerosis. Nature 592, 524-533. doi:10.1038/s41586-021-03392-8

Lin, Y.-N., Mesquita, T., Sanchez, L., Chen, Y.-H., Liu, W., Li, C., et al. (2021). Extracellular Vesicles from Immortalized Cardiosphere-Derived Cells Attenuate Arrhythmogenic Cardiomyopathy in Desmoglein-2 Mutant Mice. Eur. Heart J. 42, 3558-3571. doi:10.1093/eurheartj/ehab419

Liu, Y., He, Z., Zhang, Y., Dong, Z., Bi, Y., Kou, J., et al. (2016). Dissimilarity of Increased Phosphatidylserine-Positive Microparticles and Associated Coagulation Activation in Acute Coronary Syndromes. Coron. Artery Dis. 27, 365-375. doi:10.1097/MCA.0000000000000368

Lopatina, T., Favaro, E., Grange, C., Cedrino, M., Ranghino, A., Occhipinti, S., et al. (2018). PDGF Enhances the Protective Effect of Adipose Stem Cell-Derived Extracellular Vesicles in a Model of Acute Hindlimb Ischemia. Sci. Rep. 8. doi:10.1038/S41598-018-36143-3

Madrigal-Matute, J., Lindholt, J. S., Fernandez-Garcia, C. E., Benito-Martin, A., Burillo, E., Zalba, G., et al. (2014). Galectin-3, a Biomarker Linking Oxidative Stress and Inflammation with the Clinical Outcomes of Patients with Atherothrombosis. Jaha 3. doi:10.1161/JAHA.114.000785

Mannello, F., and Medda, V. (2012). Nuclear Localization of Matrix Metalloproteinases. Prog. Histochem. Cytochem. 47, 27-58. doi:10.1016/j. proghi.2011.12.002

Mantovani, F., Fanti, D., Tafciu, E., Fezzi, S., Setti, M., Rossi, A., et al. (2021). When Aortic Stenosis Is Not Alone: Epidemiology, Pathophysiology, Diagnosis and Management in Mixed and Combined Valvular Disease. Front. Cardiovasc. Med. 8, 744497. doi:10.3389/fcvm.2021.744497

Marchini, J. F., Miyakawa, A. A., Tarasoutchi, F., Krieger, J. E., Lemos, P., and Croce, K. (2016). Endothelial, Platelet, and Macrophage Microparticle Levels Do Not Change Acutely Following Transcatheter Aortic Valve Replacement. J. Negat. Results Biomed. 15. doi:10.1186/s12952-016-0051-2

Martin-Blazquez, A., Heredero, A., Aldamiz-Echevarria, G., Martin-Lorenzo, M., and Alvarez-Llamas, G. (2021). Non-syndromic Thoracic Aortic Aneurysm: Cellular and Molecular Insights. J. Pathol. 254, 229-238. doi:10.1002/path.5683
Martinez-Pinna, R., de Peredo, A. G., Monsarrat, B., Burlet-Schiltz, O., and Martin-Ventura, J. L. (2014). Label-free Quantitative Proteomic Analysis of Human Plasma-Derived Microvesicles to Find Protein Signatures of Abdominal Aortic Aneurysms. Prot. Clin. Appl. 8, 620-625. doi:10.1002/ prca. 201400010

Mathieu, P., Boulanger, M.-C., and Bouchareb, R. (2014). Molecular Biology of Calcific Aortic Valve Disease: Towards New Pharmacological Therapies. Expert Rev. Cardiovasc. Ther. 12, 851-862. doi:10.1586/14779072.2014.923756

Mathiyalagan, P., Liang, Y., Kim, D., Misener, S., Thorne, T., Kamide, C. E., et al. (2017). Angiogenic Mechanisms of Human CD34 + Stem Cell Exosomes in the Repair of Ischemic Hindlimb. Circ. Res. 120, 1466-1476. doi:10.1161/ circresaha.116.310557

McEvoy, J. W., Blaha, M. J., DeFilippis, A. P., Budoff, M. J., Nasir, K., Blumenthal, R. S., et al. (2010). Coronary Artery Calcium Progression: An Important Clinical Measurement? J. Am. Coll. Cardiol. 56, 1613-1622. doi:10.1016/j. jacc.2010.06.038

Méndez-Barbero, N., Gutiérrez-Muñoz, C., and Blanco-Colio, L. (2021). Cellular Crosstalk between Endothelial and Smooth Muscle Cells in Vascular wall Remodeling. Ijms 22, 7284. doi:10.3390/ijms22147284

Michel, J.-B., Jondeau, G., and Milewicz, D. M. (2018). From Genetics to Response to Injury: Vascular Smooth Muscle Cells in Aneurysms and Dissections of the Ascending Aorta. Cardiovasc. Res. 114, 578-589. doi:10.1093/cvr/cvy006

Michel, J.-B., Martin-Ventura, J.-L., Egido, J., Sakalihasan, N., Treska, V., Lindholt, J., et al. (2011). Novel Aspects of the Pathogenesis of Aneurysms of the Abdominal Aorta in Humans. Cardiovasc. Res. 90, 18-27. doi:10.1093/cvr/ cvq337

Milewicz, D. M., and Ramirez, F. (2019). Therapies for Thoracic Aortic Aneurysms and Acute Aortic Dissections. Atvb 39, 126-136. doi:10.1161/ATVBAHA.118. 310956

Mobarrez, F., Egberg, N., Antovic, J., Bröijersen, A., Jörneskog, G., and Wallén, H. (2012). Release of Endothelial Microparticles In Vivo during Atorvastatin Treatment; A Randomized Double-Blind Placebo-Controlled Study. Thromb. Res. 129, 95-97. doi:10.1016/j.thromres.2011.09.027

Mobarrez, F., He, S., Bröijersen, A., Wiklund, B., Antovic, A., Antovic, J., et al. (2011). Atorvastatin Reduces Thrombin Generation and Expression of Tissue Factor, P-Selectin and GPIIIa on Platelet-Derived Microparticles in Patients with Peripheral Arterial Occlusive Disease. Thromb. Haemost. 106, 344-352. doi:10.1160/TH10-12-0810

Mohler, E. R., Gannon, F., Reynolds, C., Zimmerman, R., Keane, M. G., and Kaplan, F. S. (2001). Bone Formation and Inflammation in Cardiac Valves. Circulation 103, 1522-1528. doi:10.1161/01.CIR.103.11.1522

Momen-Heravi, F., Getting, S. J., and Moschos, S. A. (2018). Extracellular Vesicles and Their Nucleic Acids for Biomarker Discovery. Pharmacol. Ther. 192, 170-187. doi:10.1016/j.pharmthera.2018.08.002

Monzack, E. L., and Masters, K. S. (2011). Can Valvular Interstitial Cells Become True Osteoblasts? A Side-By-Side Comparison. J. Heart Valve Dis. 20, 449-463. Available at: https://pubmed.ncbi.nlm.nih.gov/21863660/(Accessed January 4, 2022).

New, S. E. P., Goettsch, C., Aikawa, M., Marchini, J. F., Shibasaki, M., Yabusaki, K., et al. (2013). Macrophage-Derived Matrix Vesicles. Circ. Res. 113, 72-77. doi:10.1161/CIRCRESAHA.113.301036

Ngai, D., Lino, M., Rothenberg, K. E., Simmons, C. A., Fernandez-Gonzalez, R., Bendeck, M. P., et al. (2020). DDR1 (Discoidin Domain Receptor-1)-RhoA (Ras Homolog Family Member A) Axis Senses Matrix Stiffness to Promote Vascular Calcification. Atvb 40, 1763-1776. doi:10.1161/ATVBAHA.120.314697

Nkomo, V. T., Gardin, J. M., Skelton, T. N., Gottdiener, J. S., Scott, C. G., and Enriquez-Sarano, M. (2006). Burden of Valvular Heart Diseases: a PopulationBased Study. The Lancet 368, 1005-1011. doi:10.1016/S0140-6736(06)69208-8 Nomura, S. (2017). Extracellular Vesicles and Blood Diseases. Int. J. Hematol. 105, 392-405. doi:10.1007/s12185-017-2180-x

Nomura, S., Inami, N., Iwasaka, T., and Liu, Y. (2004). Platelet Activation Markers, Microparticles and Soluble Adhesion Molecules Are Elevated in Patients with Arteriosclerosis Obliterans: Therapeutic Effects by Cilostazol and Potentiation by Dipyridamole. Platelets 15, 167-172. doi:10.1080/09537100410001682779

Norgren, L., Hiatt, W. R., Dormandy, J. A., Nehler, M. R., Harris, K. A., Fowkes, F. G. R., et al. (2007). Inter-Society Consensus for the Management of Peripheral Arterial Disease (TASC II). J. Vasc. Surg. 45, S5-S67. doi:10.1016/j.jvs.2006. 12.037 
O’Brien, C. G., Ozen, M. O., Ikeda, G., Vaskova, E., Jung, J. H., Bayardo, N., et al. (2021). Mitochondria-Rich Extracellular Vesicles Rescue Patient-specific Cardiomyocytes from Doxorubicin Injury. JACC: CardioOncology 3, 428-440. doi:10.1016/j.jaccao.2021.05.006

O’Brien, K. D., Kuusisto, J., Reichenbach, D. D., Ferguson, M., Giachelli, C., Alpers, C. E., et al. (1995). Osteopontin Is Expressed in Human Aortic Valvular Lesions. Circulation 92, 2163-2168. doi:10.1161/01.CIR.92.8.2163

O'Brien, K. D. (2006). Pathogenesis of Calcific Aortic Valve Disease. Atvb 26, 1721-1728. doi:10.1161/01.ATV.0000227513.13697.ac

Ohtsuka, M., Sasaki, K.-i., Ueno, T., Seki, R., Nakayoshi, T., Koiwaya, H., et al. (2013). Platelet-derived Microparticles Augment the Adhesion and Neovascularization Capacities of Circulating Angiogenic Cells Obtained from Atherosclerotic Patients. Atherosclerosis 227, 275-282. doi:10.1016/j. atherosclerosis.2013.01.040

O’Neill, W. C., Han, K. H., Schneider, T. M., and Hennigar, R. A. (2015). Prevalence of Nonatheromatous Lesions in Peripheral Arterial Disease. Atvb 35, 439-447. doi:10.1161/ATVBAHA.114.304764

Osman, L., Yacoub, M. H., Latif, N., Amrani, M., and Chester, A. H. (2006). Role of Human Valve Interstitial Cells in Valve Calcification and Their Response to Atorvastatin. Circulation 114. doi:10.1161/CIRCULATIONAHA.105.001115

Owens, D. S., Budoff, M. J., Katz, R., Takasu, J., Shavelle, D. M., Carr, J. J., et al. (2012). Aortic Valve Calcium Independently Predicts Coronary and Cardiovascular Events in a Primary Prevention Population. JACC: Cardiovasc. Imaging 5, 619-625. doi:10.1016/j.jcmg.2011.12.023

Pan, H., Xue, C., Auerbach, B. J., Fan, J., Bashore, A. C., Cui, J., et al. (2020). SingleCell Genomics Reveals a Novel Cell State during Smooth Muscle Cell Phenotypic Switching and Potential Therapeutic Targets for Atherosclerosis in Mouse and Human. Circulation 142, 2060-2075. doi:10.1161/ CIRCULATIONAHA.120.048378

Passos, L. S. A., Lupieri, A., Becker-Greene, D., and Aikawa, E. (2020). Innate and Adaptive Immunity in Cardiovascular Calcification. Atherosclerosis 306, 59-67. doi:10.1016/j.atherosclerosis.2020.02.016

Patel, N., Chin, D. D., and Chung, E. J. (2021). Exosomes in Atherosclerosis, a Double-Edged Sword: Their Role in Disease Pathogenesis and Their Potential as Novel Therapeutics. AAPS J. 23. doi:10.1208/s12248-021-00621-w

Petsophonsakul, P., Burgmaier, M., Willems, B., Heeneman, S., Stadler, N., Gremse, F., et al. (2021). Nicotine Promotes Vascular Calcification via Intracellular Ca2+-Mediated, Nox5-Induced Oxidative Stress, and Extracellular Vesicle Release in Vascular Smooth Muscle Cells. Cardiovasc. Res. doi:10.1093/cvr/cvab244

Petsophonsakul., P., Furmanik, M., Forsythe, R., Dweck, M., Schurink, G. W., Natour, E., et al. (2019). Role of Vascular Smooth Muscle Cell Phenotypic Switching and Calcification in Aortic Aneurysm Formation. Atvb 39, 1351-1368. doi:10.1161/ATVBAHA.119.312787

Pinard, A., Jones, G. T., and Milewicz, D. M. (2019). Genetics of Thoracic and Abdominal Aortic Diseases. Circ. Res. 124, 588-606. doi:10.1161/ CIRCRESAHA.118.312436

Poredoš, P., Cevc, M., and Blinc, A. (2021). Characteristics of Atherosclerosis in Femoropopliteal Artery and its Clinical Relevance. Atherosclerosis 335, 31-40. doi:10.1016/j.atherosclerosis.2021.09.012

Preston, R. A., Jy, W., Jimenez, J. J., Mauro, L. M., Horstman, L. L., Valle, M., et al. (2003). Effects of Severe Hypertension on Endothelial and Platelet Microparticles. Hypertension 41, 211-217. doi:10.1161/01.HYP.0000049760.15764.2D

Rajamannan, N. M., Nealis, T. B., Subramaniam, M., Pandya, S., Stock, S. R., Ignatiev, C. I., et al. (2005). Calcified Rheumatic Valve Neoangiogenesis Is Associated with Vascular Endothelial Growth Factor Expression and Osteoblast-like Bone Formation. Circulation 111, 3296-3301. doi:10.1161/ CIRCULATIONAHA.104.473165

Rajamannan, N. M., Subramaniam, M., Rickard, D., Stock, S. R., Donovan, J., Springett, M., et al. (2003). Human Aortic Valve Calcification Is Associated with an Osteoblast Phenotype. Circulation 107, 2181-2184. doi:10.1161/01.CIR. 0000070591.21548 .69

Rogers, M. A., Buffolo, F., Schlotter, F., Atkins, S. K., Lee, L. H., Halu, A., et al. (2020a). Annexin A1-dependent Tethering Promotes Extracellular Vesicle Aggregation Revealed with Single-Extracellular Vesicle Analysis. Sci. Adv. 6. doi:10.1126/sciadv.abb1244

Rogers, M. A., Chen, J., Nallamshetty, S., Pham, T., Goto, S., Muehlschlegel, J. D., et al. (2020b). Retinoids Repress Human Cardiovascular Cell Calcification with
Evidence for Distinct Selective Retinoid Modulator Effects. Atvb 40, 656-669. doi:10.1161/ATVBAHA.119.313366

Rosińska, J., Łukasik, M., and Kozubski, W. (2017). The Impact of Vascular Disease Treatment on Platelet-Derived Microvesicles. Cardiovasc. Drugs Ther. 31, 627-644. doi:10.1007/s10557-017-6757-7

Roth, G. A., Johnson, C., Abajobir, A., Abd-Allah, F., Abera, S. F., Abyu, G., et al. (2017). Global, Regional, and National Burden of Cardiovascular Diseases for 10 Causes, 1990 to 2015. J. Am. Coll. Cardiol. 70, 1-25. doi:10.1016/j.jacc.2017. 04.052

Russell, A. E., Sneider, A., Witwer, K. W., Bergese, P., Bhattacharyya, S. N., Cocks, A., et al. (2019). Biological Membranes in EV Biogenesis, Stability, Uptake, and Cargo Transfer: an ISEV Position Paper Arising from the ISEV Membranes and EVs Workshop. J. Extracellular Vesicles 8, 1684862. doi:10.1080/20013078. 2019.1684862

Ryu, J.-H., Jeon, E.-Y., and Kim, S.-J. (2019). Indoxyl Sulfate-Induced Extracellular Vesicles Released from Endothelial Cells Stimulate Vascular Smooth Muscle Cell Proliferation by Inducing Transforming Growth Factor-Beta Production. J. Vasc. Res. 56, 129-138. doi:10.1159/000496796

Saenz-Pipaon, G., San Martín, P., Planell, N., Maillo, A., Ravassa, S., Vilas-Zornoza, A., et al. (2020). Functional and Transcriptomic Analysis of Extracellular Vesicles Identifies Calprotectin as a New Prognostic Marker in Peripheral Arterial Disease (PAD). J. Extracellular Vesicles 9, 1729646. doi:10.1080/ 20013078.2020.1729646

Saenz-Pipaon, G., Martinez-Aguilar, E., Orbe, J., González Miqueo, A., FernandezAlonso, L., Paramo, J. A., et al. (2021). The Role of Circulating Biomarkers in Peripheral Arterial Disease. Ijms 22, 3601. doi:10.3390/ijms22073601

Sahoo, S., Adamiak, M., Mathiyalagan, P., Kenneweg, F., Kafert-Kasting, S., and Thum, T. (2021). Therapeutic and Diagnostic Translation of Extracellular Vesicles in Cardiovascular Diseases. Circulation 143, 1426-1449. doi:10. 1161/CIRCULATIONAHA.120.049254

Sakalihasan, N., Limet, R., and Defawe, O. (2005). Abdominal Aortic Aneurysm. The Lancet 365, 1577-1589. doi:10.1016/S0140-6736(05)66459-8

Schiro, A., Wilkinson, F. L., Weston, R., Smyth, J. V., Serracino-Inglott, F., and Alexander, M. Y. (2015). Elevated Levels of Endothelial-Derived Microparticles and Serum CXCL9 and SCGF- $\beta$ Are Associated with Unstable Asymptomatic Carotid Plaques. Sci. Rep. 5. doi:10.1038/srep16658

Shah, R., Patel, T., and Freedman, J. E. (2018). Circulating Extracellular Vesicles in Human Disease. N. Engl. J. Med. 379, 2179-2181. doi:10.1056/NEJMc1813170

Shanahan, C. M., Crouthamel, M. H., Kapustin, A., and Giachelli, C. M. (2011). Arterial Calcification in Chronic Kidney Disease: Key Roles for Calcium and Phosphate. Circ. Res. 109, 697-711. doi:10.1161/CIRCRESAHA.110.234914

Simak, J., Gelderman, M. P., Yu, H., Wright, V., and Baird, A. E. (2006). Circulating Endothelial Microparticles in Acute Ischemic Stroke: A Link to Severity, Lesion Volume and Outcome. J. Thromb. Haemost. 4, 1296-1302. doi:10.1111/j.15387836.2006.01911.x

Sinning, J.-M., Losch, J., Walenta, K., Böhm, M., Nickenig, G., and Werner, N. (2011). Circulating CD31+/Annexin V+ Microparticles Correlate with Cardiovascular Outcomes. Eur. Heart J. 32, 2034-2041. doi:10.1093/ eurheartj/ehq478

Sorrentino, T. A., Duong, P., Bouchareychas, L., Chen, M., Chung, A., Schaller, M. S., et al. (2020). Circulating Exosomes from Patients with Peripheral Artery Disease Influence Vascular Cell Migration and Contain Distinct microRNA Cargo. JVS: Vasc. Sci. 1, 28-41. doi:10.1016/j.jvssci.2020.02.001

Sossong, V., Helbing, T., Beyersdorf, F., Olschewski, M., Bode, C., Diehl, P., et al. (2008). Increased Levels of Circulating Microparticles in Patients with Severe Aortic Valve Stenosis. Thromb. Haemost. 99, 711-719. doi:10.1160/TH07-05-0334 Spinosa, M., Lu, G., Su, G., Bontha, S. V., Gehrau, R., Salmon, M. D., et al. (2018). Human Mesenchymal Stromal Cell-derived Extracellular Vesicles Attenuate Aortic Aneurysm Formation and Macrophage Activation via microRNA-147. FASEB j. 32, 6038-6050. doi:10.1096/fj.201701138RR

Sritharen, Y., Enriquez-Sarano, M., Schaff, H. V., Casaclang-Verzosa, G., and Miller, J. D. (2017). Pathophysiology of Aortic Valve Stenosis: Is it Both Fibrocalcific and Sex Specific? Physiology 32, 182-196. doi:10.1152/physiol. 00025.2016

Suades, R., Padró, T., Alonso, R., Mata, P., and Badimon, L. (2015). High Levels of TSP1+/CD142+ Platelet-Derived Microparticles Characterise Young Patients with High Cardiovascular Risk and Subclinical Atherosclerosis. Thromb. Haemost. 114, 1310-1321. doi:10.1160/TH15-04-0325 
Suades, R., Padró, T., Crespo, J., Ramaiola, I., Martin-Yuste, V., Sabaté, M., et al. (2016). Circulating Microparticle Signature in Coronary and Peripheral Blood of ST Elevation Myocardial Infarction Patients in Relation to Pain-To-PCI Elapsed Time. Int. J. Cardiol. 202, 378-387. doi:10.1016/j.ijcard.2015.09.011

Tan, K. T., Tayebjee, M. H., Lynd, C., Blann, A. D., and Lip, G. Y. H. (2005). Platelet Microparticles and Soluble P Selectin in Peripheral Artery Disease: Relationship to Extent of Disease and Platelet Activation Markers. Ann. Med. 37, 61-66. doi:10.1080/07853890410018943

Tani, T., Fujiwara, M., Orimo, H., Shimizu, A., Narisawa, S., Pinkerton, A. B., et al. (2020). Inhibition of Tissue-nonspecific Alkaline Phosphatase Protects against Medial Arterial Calcification and Improves Survival Probability in the CKDMBD Mouse Model. J. Pathol. 250, 30-41. doi:10.1002/path.5346

Taylor, J., Azimi, I., Monteith, G., and Bebawy, M. (2020). Ca2+mediates Extracellular Vesicle Biogenesis through Alternate Pathways in Malignancy. J. Extracellular Vesicles 9, 1734326. doi:10.1080/20013078.2020.1734326

Théry, C., Witwer, K. W., Aikawa, E., Alcaraz, M. J., Anderson, J. D., Andriantsitohaina, R., et al. (2018). Minimal Information for Studies of Extracellular Vesicles 2018 (MISEV2018): a Position Statement of the International Society for Extracellular Vesicles and Update of the MISEV2014 Guidelines. J. Extracell. Vesicles 7, 1535750. doi:10.1080/ 20013078.2018.1535750

Tieu, A., Hu, K., Gnyra, C., Montroy, J., Fergusson, D. A., Allan, D. S., et al. (2021). Mesenchymal Stromal Cell Extracellular Vesicles as Therapy for Acute and Chronic Respiratory Diseases: A Meta-analysis. J. Extracellular Vesicles 10. doi:10.1002/jev2.12141

Timmis, A., Townsend, N., Gale, C. P., Timmis, A., Townsend, N., Gale, C. P., et al. (2020). European Society of Cardiology: Cardiovascular Disease Statistics 2019 (Executive Summary). Eur. Heart J. Qual. Care Clin. Outcomes 6, 7-9. doi:10. 1093/ehjqcco/qcz065

Torres-Fonseca, M., Galan, M., Martinez-Lopez, D., Cañes, L., Roldan-Montero, R., Alonso, J., et al. (2019). Pathophysiology of Abdominal Aortic Aneurysm: Biomarkers and Novel Therapeutic Targets. Clínica e Investigación en Arteriosclerosis (English Edition) 31, 166-177. doi:10.1016/j.arteri.2018.10. 00210.1016/j.artere.2018.10.003

Touat, Z., Lepage, L., Ollivier, V., Nataf, P., Hvass, U., Labreuche, J., et al. (2008). Dilation-dependent Activation of Platelets and Prothrombin in Human Thoracic Ascending Aortic Aneurysm. Atvb 28, 940-946. doi:10.1161/ ATVBAHA.107.158576

Touat, Z., Ollivier, V., Dai, J., Huisse, M.-G., Bezeaud, A., Sebbag, U., et al. (2006). Renewal of Mural Thrombus Releases Plasma Markers and Is Involved in Aortic Abdominal Aneurysm Evolution. Am. J. Pathol. 168, 1022-1030. doi:10. 2353/ajpath.2006.050868

Tyson, K. L., Reynolds, J. L., McNair, R., Zhang, Q., Weissberg, P. L., and Shanahan, C. M. (2003). Osteo/chondrocytic Transcription Factors and Their Target Genes Exhibit Distinct Patterns of Expression in Human Arterial Calcification. Atvb 23, 489-494. doi:10.1161/01.ATV.0000059406.92165.31

Vagida, M. S., Arakelyan, A., Lebedeva, A. M., Grivel, J. C., Shpektor, A. V., Vasilieva, E. Y., et al. (2016). Analysis of Extracellular Vesicles Using Magnetic Nanoparticles in Blood of Patients with Acute Coronary Syndrome. Biochem. Mosc. 81, 382-391. doi:10.1134/S0006297916040088

Vajen, T., Benedikter, B. J., Heinzmann, A. C. A., Vasina, E. M., Henskens, Y., Parsons, M., et al. (2017). Platelet Extracellular Vesicles Induce a Proinflammatory Smooth Muscle Cell Phenotype. J. Extracellular Vesicles 6, 1322454. doi:10.1080/20013078.2017.1322454

van der Zee, P. M., Biro', E., Ko, Y., de Winter, R. J., Hack, C. E., Sturk, A., et al. (2006). P-selectin- and CD63-Exposing Platelet Microparticles Reflect Platelet Activation in Peripheral Arterial Disease and Myocardial Infarction. Clin. Chem. 52, 657-664. doi:10.1373/clinchem.2005.057414

van Niel, G., D’Angelo, G., and Raposo, G. (2018). Shedding Light on the Cell Biology of Extracellular Vesicles. Nat. Rev. Mol. Cel Biol. 19, 213-228. doi:10. 1038/nrm.2017.125

Van Pham, P., Vu, N. B., Dao, T. T.-T., Le, H. T.-N., Phi, L. T., Huynh, O. T., et al. (2017). Extracellular Vesicles of ETV2 Transfected Fibroblasts Stimulate Endothelial Cells and Improve Neovascularization in a Murine Model of Hindlimb Ischemia. Cytotechnology 69, 801-814. doi:10.1007/s10616-017-0095-2

Villa-Bellosta, R. (2018). Synthesis of Extracellular Pyrophosphate Increases in Vascular Smooth Muscle Cells during Phosphate-Induced Calcification. Atvb 38, 2137-2147. doi:10.1161/ATVBAHA.118.311444
Villa-Bellosta, R., Wang, X., Millán, J. L., Dubyak, G. R., and O’Neill, W. C. (2011). Extracellular Pyrophosphate Metabolism and Calcification in Vascular Smooth Muscle. Am. J. Physiology-Heart Circulatory Physiol. 301, H61-H68. doi:10. 1152/ajpheart.01020.2010

Wang, Y., Jia, L., Xie, Y., Cai, Z., Liu, Z., Shen, J., et al. (2019). Involvement of Macrophage-Derived Exosomes in Abdominal Aortic Aneurysms Development. Atherosclerosis 289, 64-72. doi:10.1016/j.atherosclerosis.2019.08.016

Weber, A., Liu, S. S., Cardone, L., Rellecke, P., Sixt, S. U., Lichtenberg, A., et al. (2020). The Course of Circulating Small Extracellular Vesicles in Patients Undergoing Surgical Aortic Valve Replacement. Biomed. Res. Int. 2020, 1-12. doi:10.1155/2020/6381396

Wekesa, A. L., Cross, K. S., O’Donovan, O., Dowdall, J. F., O’Brien, O., Doyle, M., et al. (2014). Predicting Carotid Artery Disease and Plaque Instability from Cell-Derived Microparticles. Eur. J. Vasc. Endovascular Surg. 48, 489-495. doi:10.1016/j.ejvs.2014.08.007

Werner, N., Wassmann, S., Ahlers, P., Kosiol, S., and Nickenig, G. (2006). Circulating CD31+/Annexin V+Apoptotic Microparticles Correlate with Coronary Endothelial Function in Patients with Coronary Artery Disease. Atvb 26, 112-116. doi:10.1161/01.ATV.0000191634.13057.15

Wirka, R. C., Wagh, D., Paik, D. T., Pjanic, M., Nguyen, T., Miller, C. L., et al. (2019). Atheroprotective Roles of Smooth Muscle Cell Phenotypic Modulation and the TCF21 Disease Gene as Revealed by Single-Cell Analysis. Nat. Med. 25, 1280-1289. doi:10.1038/s41591-019-0512-5

Xiang, D., Li, Y., Cao, Y., Huang, Y., Zhou, L., Lin, X., et al. (2021). Different Effects of Endothelial Extracellular Vesicles and LPS-Induced Endothelial Extracellular Vesicles on Vascular Smooth Muscle Cells: Role of Curcumin and its Derivatives. Front. Cardiovasc. Med. 8. doi:10.3389/fcvm.2021.649352

Yuan, X., Bhat, O. M., Samidurai, A., Das, A., Zhang, Y., and Li, P.-L. (2020). Reversal of Endothelial Extracellular Vesicle-Induced Smooth Muscle Phenotype Transition by Hypercholesterolemia Stimulation: Role of NLRP3 Inflammasome Activation. Front. Cel Dev. Biol. 8. doi:10.3389/fcell.2020.597423

Zarà, M., Guidetti, G. F., Camera, M., Canobbio, I., Amadio, P., Torti, M., et al. (2019). Biology and Role of Extracellular Vesicles (Evs) in the Pathogenesis of Thrombosis. Ijms 20, 2840. doi:10.3390/ijms 20112840

Zeiger, F., Stephan, S., Hoheisel, G., Pfeiffer, D., Ruehlmann, C., and Koksch, M. (2000). P-selectin Expression, Platelet Aggregates, and Platelet-Derived Microparticle Formation Are Increased in Peripheral Arterial Disease. Blood Coagul. Fibrinolysis 11, 723-728. doi:10.1097/00001721-200012000-00005

Zhang, X., Jiang, Y., Huang, Q., Wu, Z., Pu, H., Xu, Z., et al. (2021). Exosomes Derived from Adipose-Derived Stem Cells Overexpressing Glyoxalase-1 Protect Endothelial Cells and Enhance Angiogenesis in Type 2 Diabetic Mice with Limb Ischemia. Stem Cel Res. Ther. 12. doi:10.1186/s13287-021-02475-7

Zhu, Q., Li, Q., Niu, X., Zhang, G., Ling, X., Zhang, J., et al. (2018). Extracellular Vesicles Secreted by Human Urine-Derived Stem Cells Promote Ischemia Repair in a Mouse Model of Hind-Limb Ischemia. Cel. Physiol. Biochem. 47, 1181-1192. doi:10.1159/000490214

Ziegler, S. G., Ferreira, C. R., Macfarlane, E. G., Riddle, R. C., Tomlinson, R. E., Chew, E. Y., et al. (2017). Ectopic Calcification in Pseudoxanthoma Elasticum Responds to Inhibition of Tissue-Nonspecific Alkaline Phosphatase. Sci. Transl. Med. 9. doi:10.1126/scitranslmed.aal1669

Conflict of Interest: The authors declare that the research was conducted in the absence of any commercial or financial relationships that could be construed as a potential conflict of interest.

Publisher's Note: All claims expressed in this article are solely those of the authors and do not necessarily represent those of their affiliated organizations, or those of the publisher, the editors and the reviewers. Any product that may be evaluated in this article, or claim that may be made by its manufacturer, is not guaranteed or endorsed by the publisher.

Copyright (C) 2022 Martin-Ventura, Roncal, Orbe and Blanco-Colio. This is an openaccess article distributed under the terms of the Creative Commons Attribution License (CC BY). The use, distribution or reproduction in other forums is permitted, provided the original author(s) and the copyright owner(s) are credited and that the original publication in this journal is cited, in accordance with accepted academic practice. No use, distribution or reproduction is permitted which does not comply with these terms. 